\title{
From Just-in-Time, to Just-in-Case, to Just-in-Worst-Case: Simple Models of a Global Supply Chain under Uncertain Aggregate Shocks
}

\author{
Bomin Jiang ${ }^{1} \cdot$ Daniel Rigobon $^{2} \cdot$ Roberto Rigobon $^{3}$
}

Published online: 15 November 2021

(c) International Monetary Fund 2021

\begin{abstract}
COVID-19 highlighted the weaknesses in the supply chain. Many have argued that a more resilient or robust supply chain is needed. But what does a robust supply chain mean? And how do firms' decisions change when taken that approach? This paper studies a very stylized model of a supply chain, where we study how the decision of a multinational corporation changes in the presence of uncertainty. The two standard theories of supply chain are just-in-time and just-in-case. Just-in-time argues in favor of pursuing efficiency, while just-in-case studies how such decision changes when the firm faces idiosyncratic risk. We find that a robust supply chain is very different specially in the presence of systemic shocks. In this case, firms need to concentrate on the worst-case. This strategy implies a supply chain where the allocation of resources and capabilities does not correspond to the standard theories studied in economics, but follow a heuristic behavioral rule called "probability matching." It has been found in nature and in experimental research that subjects appeal to probability matching when seeking survival. We find that a robust supply chain will reproduce this behavioral outcome. In fact, a multinational optimizing under uncertainty follows a probability matching which leads to an allocation that is suboptimal from the individual producer point of view, but rules out the possibility of supply disruptions.
\end{abstract}

JEL Classifications E7 $\cdot \mathrm{F} 02 \cdot \mathrm{F} 12 \cdot \mathrm{F} 13 \cdot \mathrm{L} 15$

\footnotetext{
We are grateful to the IMF for inviting us to present at 21st Jacques Polak Annual Research Conference - November 5-6, 2020. We thank David Baqaee, Gita Gopinath, Guido Lorenzoni, Margarita Starkeviciute, and Linda Tesar, for comments on our paper. We are also grateful to the editor Emine Boz and two anonymous referees for their comments. All errors are our own. Data and code will be made publicly available.
}

Roberto Rigobon rigobon@mit.edu

Extended author information available on the last page of the article 


\section{Introduction}

"Just-in-time" (JIT) manufacturing was introduced in Japan during the late 1940s and early 1950 s by Toyota, with the purpose of reducing inventories, reducing setup times, and saving costs in other aspects of the supply chain. The reasons why it started in Japan are not completely clear. Some have argued that it was a combination of limited natural resources, a lack of physical space to hold the inventories, and financial constraints that the Japanese industry faced at the end of the war. ${ }^{1}$ The cost reduction and efficiency gains of JIT became well known worldwide. Indeed, it became the standard of excellence in a short period of time and was adopted by many corporations. In fact, the globalization of the manufacturing of goods and services that started in the 1980s was, for the most part, inspired by JIT premises. Interestingly, even from the very beginning, Toyota suggested that the main risk of this strategy was its excessive reliance on suppliers - which could be less resilient and flexible than Toyota itself. Hence, a successful JIT implementation required a large emphasis on supplier development. Toyota argued that the JIT's biggest weakness was this vulnerability.

In response to those risks and seeking resilience, companies have explored other alternatives. These strategies, dubbed "just-in-case," usually recommend actions such as larger inventories, diversification of the production network, and harmonization of parts. In the end, the advice is simple: to develop flexibility and redundancy in the supply chain. Regardless of all these efforts, the world's supply chains proved to be unreliable during the COVID-19 pandemic. Either international trade frictions, quarantine restrictions, large shifts in demand (such as protective equipment), or even panic demand purchases of some products (such as toilet paper and disinfectant wipes in the USA) highlighted the fragility of supply chains in the world. As a result, many countries experienced supply disruptions for various products during the pandemic. We believe this collapse is due to a design flaw: While the just-incase approach might be appropriate for idiosyncratic shocks, it seems to have failed in the presence of an aggregate shock.

Many have argued that the solution is to have greater resilience and robustness. ${ }^{2}$ However, what exactly does it mean to have a robust supply chain? How does it differ from assuming a more severe shock? In this paper, we argue that a robust supply chain is one that addresses uncertainty instead of risk. The presence of uncertainty requires a decision maker to solve a minimax optimization problem, in which they optimize the worst case of a set of outcomes - see, for instance, Gilboa and Schmeidler (1989) for an axiomatic treatment. In this sense, robustness means more than just assuming larger shocks; it means considering the worst possible outcome of a set of models; it means shifting to "Just-in-Worst-Case."

\footnotetext{
1 See the Toyota Production System, where one of the two pillars for production is just-in-time: a type of production where "only the necessary products, at the necessary time, in the necessary quantity are manufactured, and in addition, the stock on hand is held to a minimum." Also see Plenert (2007).

2 See The FT Editorial Board (2020), Evans (2020), and Long (2020).
} 
In this paper, we present a very simple model. It introduces the idea that, in the pursuit of efficiency, a decentralized supply chain could become vulnerable to aggregate shocks. In other words, our setup reflects the well-known trade-off between efficiency and robustness. In particular, a design with greater resilience to shocks will sacrifice efficiency during normal times. We are interested in understanding the consequences of natural disasters, environmental shocks, and pandemics on the global supply chain. These shocks tend to be substantial and infrequent, but also widespread - affecting many countries and regions at the same time. Just-in-case's standard supply chain analysis studies firms facing large, frequent idiosyncratic shocks with known distribution. We study a different problem, one in which the shocks are infrequent, aggregate, and with unknown distribution. The simple model analyzes the survival of a multinational firm that purchases from small global suppliers. The suppliers decide where to locate, and locations are subject to aggregate shocks - which for simplicity are correlated with location. ${ }^{3}$ We compare two types of global supply chain arrangements and two different types of shocks. First, the small suppliers individually decide their location, and the multinational purchases the surviving suppliers' products. Second, we study the case when the multinational can choose all its suppliers' locations, thereby internalizing the location decision (i.e., the suppliers are subsidiaries of the multinational firm). From the perspective of the shocks, we compare the situation of risk versus uncertainty through two settings of random aggregate shocks. In the first case, we assume the distribution is given, while in the second case, only the distribution's support is known.

Our setup replicates many well-known results: just-in-time, a multinational internalizing an externality, etc. The purpose of reproducing those results is to compare them to the strategy implied by robust control. The robust strategy is in the spirit of a behavioral result known in psychology as probability matching. A rational individual facing a choice between two options should always choose the option with the higher payoff probability. For example, consider an individual with two choices: Option A delivers one dollar $70 \%$ of the time (zero otherwise), while option B pays one dollar only $30 \%$ of the time (and zero otherwise). A rational agent should choose option A in all instances - whether they are playing once or many times. However, experimental research has shown that this is not the case. When participants are faced with a series of these choices, they often choose by replicating the probabilities. In other words, they would pick option A $70 \%$ of the time and option B $30 \%$ of the time. Hence, the strategy is called probability matching. Several possible explanations of this phenomenon have been offered. First, one may describe the behavior as irrational. Another explanation appeals to bounded rationality. Intuitively, because it is costly for humans to process information, they will recur to heuristics when making decisions. ${ }^{4}$ A heuristic allows for a fast resolution and in fact replicates many of the (seemingly) irrational behaviors observed in sports

\footnotetext{
${ }^{3}$ Our aggregate shock is one that affects all suppliers in the world, but not all of them negatively. In other words, some suppliers could be benefited from the shock while others could be hurt. It is a form of aggregate shock in the sense that when one location is affected, the other location is not.

4 See Kahneman et al. (1982) and Kahneman and Tversky (1979).
} 
and gambling. For example - the fallacy that an event must occur because it has not happened for a while: "a coin has flipped four heads in a row, it is very unlikely that another one will occur," or thinking that a batter will get a hit because they have failed to do so for a while. In this case, the heuristic is to match the decision to the representativeness of choices. The last explanation for probability matching comes from evolutionary psychology. ${ }^{5}$ Observation of foraging species documents that the allocation of individuals matches the distribution of resources and that this behavior maximizes the survival probability of the species while also reducing the possibility that competing species invade the resource. ${ }^{6}$ In this paper, we present a model in which a fully rational agent who is ambiguity averse and internalizes the survival probability will replicate the probability matching behavior.

Our basic model has two locations: the Mountain and the Valley. ${ }^{7}$ The two locations differ only in the probability that an aggregate shock hits. We will assume the shock is extreme, such that all suppliers in the affected location perish. ${ }^{8}$ Without loss of generality, we also assume that the shock is more likely to occur in the Mountain than in the Valley. Formally, if an aggregate shock occurs in our model, then the conditional probability of the shock affecting the Mountain (or the Valley) will be $\theta$ (or $1-\theta$ ), where $\theta>1 / 2$.

Each supplier produces a single unit, or a "part." Both the cost of production and the sell price per part are held constant: in both locations, for all producers, and in any state of the world. In particular, the prices are independent of both the realization of the aggregate shock, and the number of surviving suppliers. ${ }^{9}$ However, in canonical macroeconomic and international models, this would not be the case. The demand is usually chosen such that when quantities tend to zero, prices increase and can even tend to infinity. Models based on Cobb-Douglas or CES functions have this feature, and the pricing system reflects scarcity. Nonetheless, if firms are concerned about the consequences of increasing their prices after natural disasters, or there is a law that does not allow prices to increase after such an event, then the price required to achieve the efficient allocation may never be realized. If this were known ex-ante, then it would affect the willingness of suppliers to diversify into

\footnotetext{
5 See Todd and Gigerenzer (2012).

6 See Seth (2007) for simulations replicating probability matching - that in econology is known as the ideal free distribution.

7 This example is inspired by Lo (2017) discussion on probability matching.

8 In practice, aggregate shocks may not be so severe or permanent. In keeping with the theme of this paper, we assume the worst possible outcome. See, for instance, Hallegatte (2015) and Tran et al. (2020) for discussion on the extent and duration of economic shocks due to natural disasters. For example, in November of 2020, it was still very difficult to purchase masks, hand sanitizer, and sanitary wipes in the USA. This suggests that even in a developed nation, the supply disruptions can last for a long period of time.

9 There are a few motivations for this assumption, which are discussed more in detail in Sect. 2. First, a natural disaster or other disruptive event may lead to some degree of price stickiness. While fixed prices are an extreme of stickiness, partially adjusting prices will still replicate the qualitative results of our model. Additionally, we can appeal to consumer anger in response to price gouging after natural disasters. For consumer anger, see Rotemberg $(2002,2011))$ and for price gouging laws Executive Order 13910 of March 23, 2020, Preventing Hoarding of Health and Medical Resources To Respond to the Spread of COVID-19. For examples of price gouging laws in the USA, see King and Spalding (2020).
} 
risky locations. Our model takes an extreme assumption - prices are fixed - to capture this feature of regulations and institutions. Moreover, below we include some anecdotal evidence of law enforcement and consumers' negative reactions to price gouging during the COVID-19 pandemic.

The number of suppliers grows and depends on the number of surviving suppliers. We treat each suppliers' part as a different intermediate good, and the multinational purchases as many parts as possible to sell the final product internationally. The product is more desirable the more parts it has - but it can be manufactured with a subset of the parts. This setting is equivalent to assume that the quality of the item increases with the number of parts it has. ${ }^{10}$

The parameters in the model are such that each supplier's location decision has a dominant strategy, which is not collectively optimal when the probability of global survival is taken into account. This discrepancy comes from the inability of the pricing system to compensate firms properly for moving into the Mountain. In this setting, the multinational wants to ensure its suppliers survive. Putting this differently, the multinational cares about survival, while the suppliers do not. This difference implies that the multinational might be willing to set production facilities in the Mountain to insure itself against an aggregate shock in the Valley. This part of the model captures a simple externality and the need for a diversified supply chain, but not yet a robust one.

This is where the nature of the shock matters. When the shocks have known distributions - what is known as risk or the nominal model - the multinational will exhibit behavior that takes into account all the sources of risk. This setting implies a desire for diversification, and one of the implications, for example, is that the multinational's optimal allocation of firms to the Mountain depends on the number of suppliers that have survived. There is both a marginal benefit and cost of diversification, and in general, an internal solution is found (at least under our assumptions). The multinational's policy changes dramatically when the shock has bounded uncertainty - meaning that the distribution is unknown - in the robust model. In this setting, an ambiguity-averse multinational will perform a robust control optimization. As we will see, with sufficient uncertainty the optimal allocation of firms is independent of the number of surviving firms. The robust supply chain decision, therefore, looks very different from the nominal model.

This paper includes several theoretical results worth highlighting. First, we compare the centralized and decentralized solutions to the model. We show a corner solution of the decentralized allocation (all firms locate themselves in the Valley) - exposing the multinational to an aggregate shock to the Valley. This result contrasts with the internal solution (a proportion larger than zero of firms in the Mountain) of the centralized allocation. Individual suppliers maximize efficiency (or productivity), while the multinational maximizes survival. This result is known and simple to understand - the multinational internalizes the survival externality.

\footnotetext{
${ }^{10}$ It is very common in supply chain management to assume that if one good or part is missing, the whole product cannot be manufactured. By relaxing this assumption, we can eliminate the typical assumptions behind just-in-case theories and concentrate on the robustness aspect.
} 
Second, we study the implications of risk and uncertainty in the probability distribution of the aggregate shock. We depart from the assumption of the first part of our paper: that the value of $\theta$, the conditional probability that the aggregate shock affects the Mountain, is known. We first study what occurs when $\theta$ is risky; for example, we assume it is distributed between $[\bar{\theta}-\Delta, \bar{\theta}+\Delta]$ according to some a priori known distribution. This exercise represents a risky setup - the nominal model. We compare it to the uncertain setup where the multinational only knows that $\theta \in[\bar{\theta}-\Delta, \bar{\theta}+\Delta]$, but the distribution is unknown. This is the case of uncertainty, and the optimal control problem requires a robust approach. Being averse to ambiguity, the individual suppliers and the multinational maximize the expected profit assuming the worst-case value of $\theta$. For example, if $\bar{\theta}>1 / 2$ but the support of $\theta$ contains $1 / 2$, then the optimal robust control will optimize as if $\theta=1 / 2$. The diversification resulting from robust control replicates probability matching and is very different from the diversification obtained in a traditional expected utility maximization problem with large variance or risk aversion.

In traditional supply chain literature of just-in-time and just-in-case, most of the analysis concentrates on idiosyncratic shocks of suppliers. As a result, building a supply chain with a precisely calculated amount of inventory can maximize efficiency and profit. Since the COVID-19 outbreak and the consequently supply chain disruptions, it is evident that aggregate shock on macroeconomic situation matters. In macroeconomics, the analysis of aggregate shock relies heavily on mathematical models, which are subject to modeling assumptions and model calibrations. Recently, some macroeconomic research starts to consider model uncertainty and robustness. ${ }^{11}$ With model uncertainty, robust decision rules seek to maximize the payoff in the worst-case scenario of a set of potential models.

This modeling choice is also supported by theoretical and empirical literature in ambiguity aversion. Ambiguity aversion refers to the behavioral phenomenon where people prefer variations with known distribution over unknown distribution. This phenomenon can be explained by people maximizing their utility for the worst-case scenario when the distribution is unknown, as in Gilboa and Schmeidler (1989). Since global supply chain disruptions have catastrophic impacts on social welfare, and the probability of such disruptions is not accurately known, uncertainty and robust decision rules are the proper tools for analysis and policy recommendations. In our case, the diversification implied by robust decision rules is very different from the diversification that could be obtained in a standard risk-averse model by either increasing the variance or the risk aversion to infinity.

Finally, we study what happens when prices and costs of production differ across locations. We compare three settings for the global supply chain: (i) the decentralized myopic setting that always chooses a corner solution, except when prices and costs are at the knife-edge when the value of both locations is the same; (ii) the probability matching heuristic where the allocation of firms coincides with the probabilities of survival in each location; and (iii) the optimal allocation by the multinational.

\footnotetext{
11 See Hanson and Sargent (2011) for robust control in general and Strzalecki (2011) for the axiomatization of multiplier preferences, and many others.
} 
We show that the decentralized solution can replicate the centralized solution when the value in the Mountain is equal to the value in the Valley. Our model justifies why governmental subsidies can help the decentralized economy achieve a robust solution. Our discussion was motivated by Japan's policy actions during the summer of 2020, where Japan set up a fund to compensate firms that diversify out of China. ${ }^{12}$ Of course, the decision could have been driven by political aspects not considered in this paper, but our model at least rationalizes economically why such an industrial policy makes sense.

For each simple model, we draw policy implications motivated by the recent experience with the pandemic. Summarized in the end, all of these policy implications have a simple message: Robustness is under-supplied.

This paper is organized as follows: Sect. 2 introduces some empirical evidence of supply shocks and price gouging restrictions during the COVID-19 pandemic. Section 3 presents our simple model of optimal control of a supply chain, with accompanying simulations. In Sect. 4, we introduce risk and uncertainty and discuss the differences between the optimal solutions of these settings. Next, Sect. 5 studies the impact of different costs in the Mountain and the Valley, and finally, Sect. 7 concludes with policy implications and future research.

\subsection{Literature Review}

Probability Matching Our model provides a control problem rationalization of probability matching. When a game similar to ours is presented to individuals, experiments show that individuals tend to locate at the Valley roughly with probability $\theta$, and locate at the Mountain roughly with probability $1-\theta$. This experimental result is known as probability matching in the literature. ${ }^{13}$ Many different theoretical approaches to behavior are developed to explain this phenomenon that humans prefer probability matching over rational expected utility maximization. Some early work suggests that it is a behavioral limitation due to bounded rationality, but more recent literature attributes that to learning strategies. Vulkan (2000) and Gaissmaier and Schooler (2008) argue that people would consistently try to learn patterns of the outcome series in a repeated game even when they are informed that the series is completely i.i.d. As a result, if the outcome series is truly i.i.d. as many of the earlier models assume, then probability matching seems irrational. On the other hand, if there is, in fact, a pattern in the series, probability matching claims a higher expected reward in the long run by gradually learning the patterns. Other literature suggests that probability matching is related to the growth pattern of a group of individuals. For example, Brennan and Lo (2011) conclude that if two choices result in similar growth rates, then deterministic decision rule prevails. On the other hand, if two choices result in drastically different growth rates, then probability matching gives an evolutionary advantage over the deterministic decision rules.

\footnotetext{
12 See Bloomberg News (2020).

${ }^{13}$ See, for example, Fiorina (1971), Morse and Runquist (1960), Vulkan (2000), and Brennan and Lo (2011).
} 
In our model, the intuition of the mechanism is simple: What is individually optimal is not collectively optimal. The reason is that the survival of firms in our model has a global externality from the inability of firms to coordinate - the increase in the number of firms that could produce - that given our setup the decentralized market does not take into account. When the multinational solves the model, however, it internalizes this effect, and it forces firms to do something that looks locally irrational. As said before, locating firms in the Mountain provides insurance to the multinational when an aggregate shock to the Valley takes place. That insurance is extremely valuable when uncertainty is present.

Supply Chain The literature on the supply chain is extensive and impossible to summarize in a few paragraphs. There are, however, aspects that have been discussed in the literature that are relevant to the model we present here.

Aggregate shocks like COVID-19 has a significant implication of global supply chain risk management. Earlier empirical research describes this as supply chain flexibility, see Vickery et al. (1999). That paper defines flexibility as the ability to adapt to aggregate shocks. It shows through correlation analysis that supply chain flexibility is critical to the long-run survival of an organization. On the other hand, flexibility may affect the immediate competitiveness of the firm in the short run.

The vulnerability of the global supply chain to identical suppliers has already raised some concerns in the industry. Wagner and Bode (2006) studied questionnaires from company executives in Germany and concludes that a firm's dependence on single-type customers and suppliers is the largest contributor to a firm's exposure to supply chain risk.

In recent years, the question of whether to integrate suppliers or not has been receiving more and more attention to supply management. The existing empirical literature has been studying this issue by looking at the elasticity of substitution of produces, see Antràs and Chor (2013) and Alfaro et al. (2019). When the demand for the final product is elastic, and inputs are not substitutable, firms choose not to integrate upstream suppliers. On the other hand, when the demand for the final product is inelastic, and inputs are substitutable, firms choose to integrate upstream suppliers. This finding shows that firms' supply chain decisions are optimal for the deterministic case, but not necessarily when an aggregate shock hits.

Apart from the works highlighted above, two groups of the literature align with the spirit of this paper.

First, there is ample literature discussing the organization of the supply chain. Following Antràs (2020), global supply chains can be viewed through different lenses. First, the value-added approach where firms allocate production internationally, and each stage of production contributes to the final product. In general, this literature concentrates on countries and industries as the unit of analysis. Second, the firm-level perspective - started by Melitz (2003) - offers an alternative to the aggregate view of the first approach. In this literature, the firms are the unit of analysis, and they are the ones that decide whether or not to participate in global supply chains. Both of these approaches assume there is no informational problem. This is relaxed by the relational view of supply chains. In this view, firms and suppliers face contracting problems - moral hazard or incomplete contracts - and therefore enter in relation to solve the informational problem. The main question it addresses is the 
organizational structure of the firm. The boundary of the firm in the global supply chain started with the seminal contribution of Antras (2003). The author discusses how incomplete contracts determine whether a firm should be integrated internationally versus enter into arms-length negotiations. ${ }^{14}$ Finally, Yeaple (2003) studies the vertical and horizontal integration of multinationals.

Second, the literature on supply resilience highlights that resilience can be obtained by organizational robustness or organizational flexibility. See, for instance, Ambulkar et al. (2015), Töyli et al. (2013), Zhao and You (2019), Saenz et al. (2015), Durach and Machuca (2018), Helpman et al. (2004), and the references therein. Most of this literature, however, has two features. One is very related to our model - the literature advises that a robust supply chain can be achieved by working closely with the suppliers. In the spirit of our model, that is equivalent to when the multinational decides the global allocation problem. The second aspect is that most of these papers think about the robustness of a supply chain in response to shocks to the firms - i.e., the robustness to idiosyncratic shocks.

\section{COVID-19 and Supply Chains}

\subsection{Heterogeneous Supply Chain Disruptions}

As has been argued by many, COVID-19 is a hybrid crisis. It has both supply and demand components, so understanding the magnitude and relevance of a single supply chain disruption is difficult. Furthermore, the demand/supply shock combinations are country-specific.

From the anecdotal point of view, many products suffered shortages during the COVID pandemic - hand sanitizer, toilet paper, meat products, beer, etc. The demand for these products, especially hand sanitizer, did not decline; therefore, it is clear that supply disruptions were present in many of them. The disruptions, interestingly, were not specific to China. In fact, in Fig. 1 we present the value of trade merchandise for the world (top panel), the USA, and China (left, and right bottom panels). These data come from the WTO.

For each region, the indices have been normalized to one in January of 2006. As can be seen, the 2008 financial crisis had a huge impact on all of them: World trade declined by almost a half (from 1.73 to 1.01 ), in the USA the decline was from 1.57 to 1.05 , and in China, the value of trade dropped from 2.10 to 0.99 .

On the other hand, the impact of COVID was heterogeneous. World trade experienced a small decline; comparing trade volumes in Q3 2020 to Q3 2019, the drop was only $6.2 \%$. In the case of China, trade actually increased by $3.7 \%$, while it declined by $23 \%$ for the USA.

In summary, the trade data show the distinct effects of the pandemic on the supply chains of the USA and China. It is exactly this heterogeneity that we seek to capture through our model's use of the Mountain and Valley.

14 See Antràs and De Gortari (2020), Antràs and Chor (2018), and Antras (2015). 


\subsection{Prices and Supply Shocks}

It is difficult to measure the impact of the supply disruption by only the value of trade, but a study of prices proves a much simpler exercise. Figures 2 and 3 present the inflation rate of different sectors and items. All the data come from the Bureau of Labor Statistics (BLS), the CPI database. We selected all the seasonal adjusted monthly series aggregated at the US level. There are 317 categories; for illustrative purposes, the figures only present the most aggregate ones (about 97).

The figures are sorted by the size of the price deflation or inflation. As can be seen, there is tremendous heterogeneity, although the median annualized inflation rate is north of $10 \%$. Several aspects are worth highlighting.

First, if the demand shock of COVID were to dominate any supply disruption, then we should observe most sectors experiencing deflation. Empirically, this was not the case - of the 313 BLS series for which inflation could be computed between January and May, ${ }^{15}$ only 119 experienced deflation. Consequently, more than $60 \%$ of the indices computed by the BLS experienced inflation at a time when the economy was undergoing strict lockdowns. We believe this inflation reflects the supply chain disruptions occurring during the pandemic.

Second, the sectors where prices declined are concentrated in Energy, Transportation Apparel, Tourism, and Jewelry. ${ }^{16}$ The sectors that experienced price increases are related to Food, Household products, Beverages, and Medical Supplies. ${ }^{17}$ As we might have expected, more essential products experienced greater inflation during the pandemic.

Third, extending the analysis to September does not change the qualitative results - except that the supply shock dominates more than the demand shock - which should have been expected given that the US economy opened up. From January to September, only 99 of the 313 series ID's computed by the BLS experienced any form of deflation. Furthermore, the repressed sectors were still Energy, Transportation, Apparel, Tourism, and Recreation. Interestingly, in these sectors there is no report of supply disruptions - either in the USA or globally. Deflation in these sectors is exclusively driven by the demand shock. The sectors experiencing inflation in September and May are similar and are concentrated in Food, Beverages, Household

\footnotetext{
$\overline{15}$ Several sectors or items have prices collected at different frequencies.

${ }^{16}$ In fact, the sectors with deflation higher than $2 \%$ are Motor fuel, Energy commodities, Fuel oil and other fuels, Public transportation, Energy, Motor vehicle insurance, Lodging away from home, Women's apparel, Transportation, Private transportation, Transportation services, Women's and girls' apparel, Infants' and toddlers' apparel, Apparel, Footwear, Men's apparel, Men's and boys' apparel, Boys' apparel, Jewelry and watches, Nondurables, Girls' apparel, Commodities, Other recreational goods, and Sporting goods.

${ }^{17}$ The list of the items which experienced more than $2 \%$ inflation, in order from the lowest inflation (2\%) to the highest (15\%), are: Medical care services, Alcoholic beverages at home, Fresh fruits, Beverage materials including coffee and tea, Fresh vegetables, Other recreation services, Food and beverages, Bakery products, Food, Other meats, Housekeeping supplies, Fish and seafood, Cereals and cereal products, Processed fruits and vegetables, Other foods, Dairy and related products, Juices and nonalcoholic drinks, Pork, Poultry, Eggs, and Beef and veal.
} 

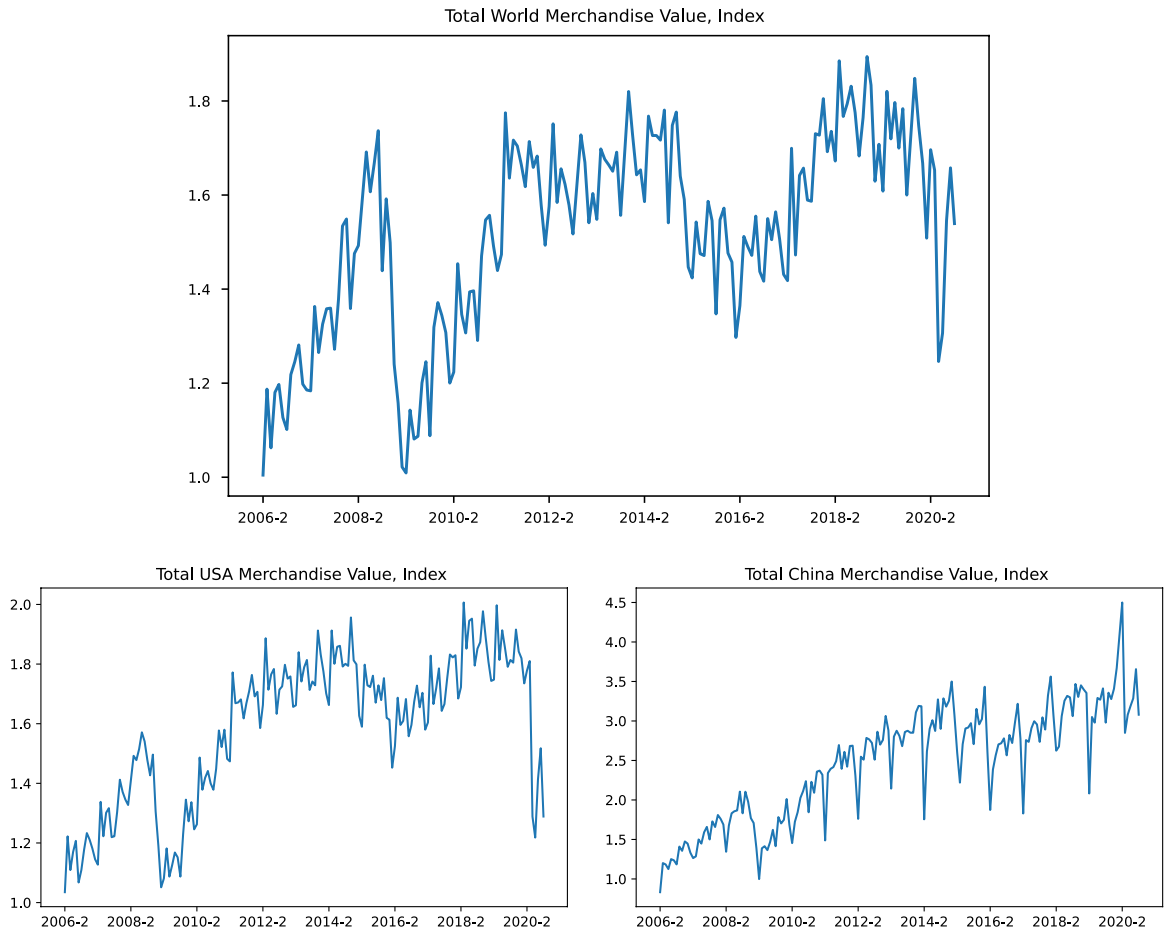

Fig. 1 Merchandise Value for World, USA, and China

Products, and Medical Supplies. In all these sectors, we have reports of supply disruptions - at least anecdotally.

In summary, analysis of prices in the USA by sector makes clear that supply chains failed to deliver basic products. Items such as food, beverages, household products, and medical supplies experienced large inflation. In fact, in these types of essential products many countries established much-needed anti-price gouging laws during the pandemic. Therefore, the inflation that we observe is not as high as the one that would have existed without the restrictions. This is the topic of the next subsection.

\subsection{Price Gouging}

One of the important assumptions of our model is that prices do not adjust fully to the aggregate shocks. In general, prices may deviate from equilibrium due to stickiness, as has been studied in the relevant macro literature. See, for instance, Caballero and Engel (2006) and references therein for theoretical results and Anderson et al. (2015) for some empirical evidence. In the case of large aggregate shocks, we also motivate the fixed-price assumption by the existence of price gouging laws in many countries during the pandemic - either because of fairness considerations or 


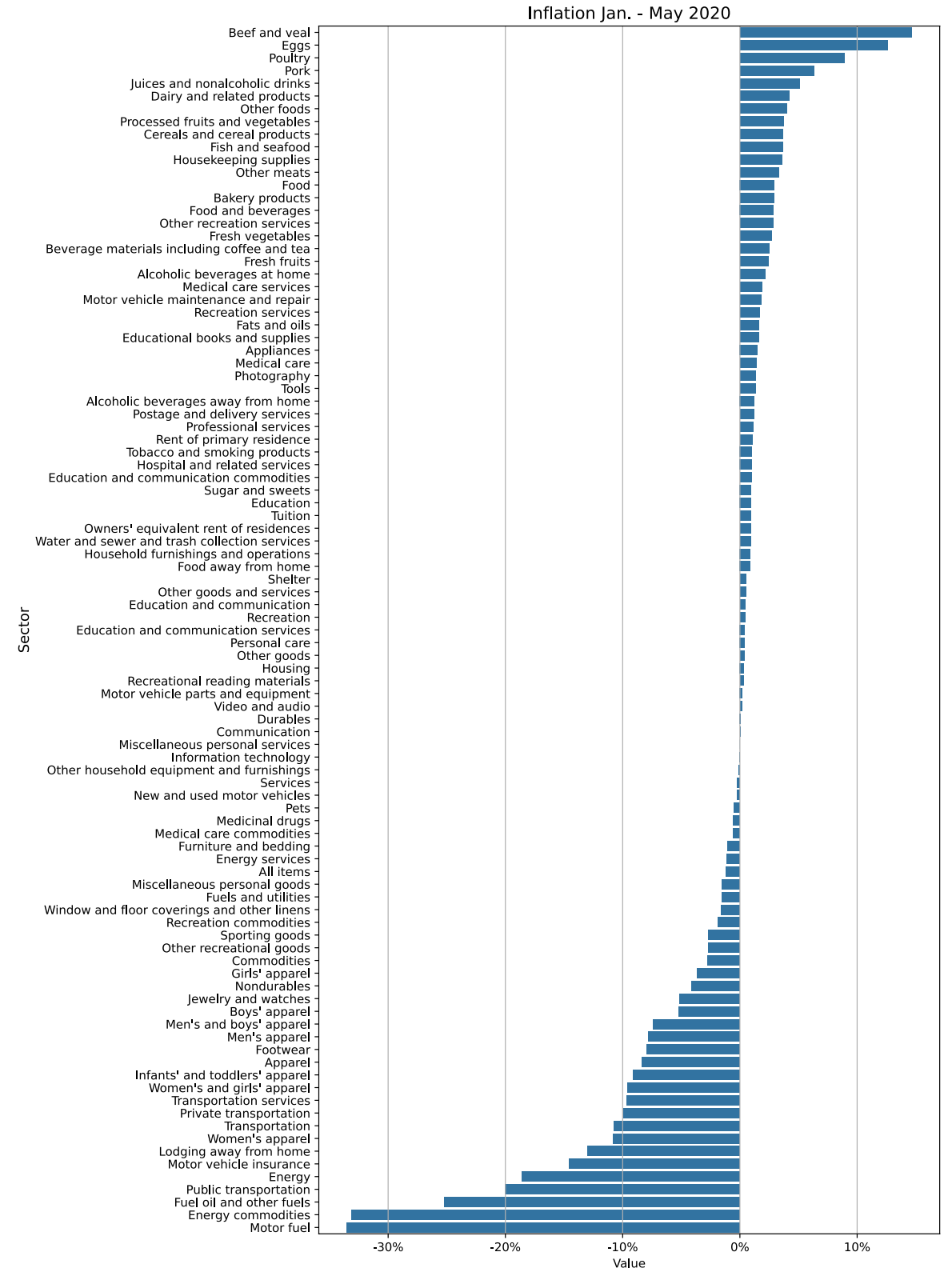

Fig. 2 US Inflation by sector between January and May of 2020

consumer anger. In this subsection, we discuss the origin and relevant evidence of this latter motivation.

When facing large aggregate shocks, the price of essential goods cannot float freely as assumed by the classic general equilibrium model. Take COVID-19 as 


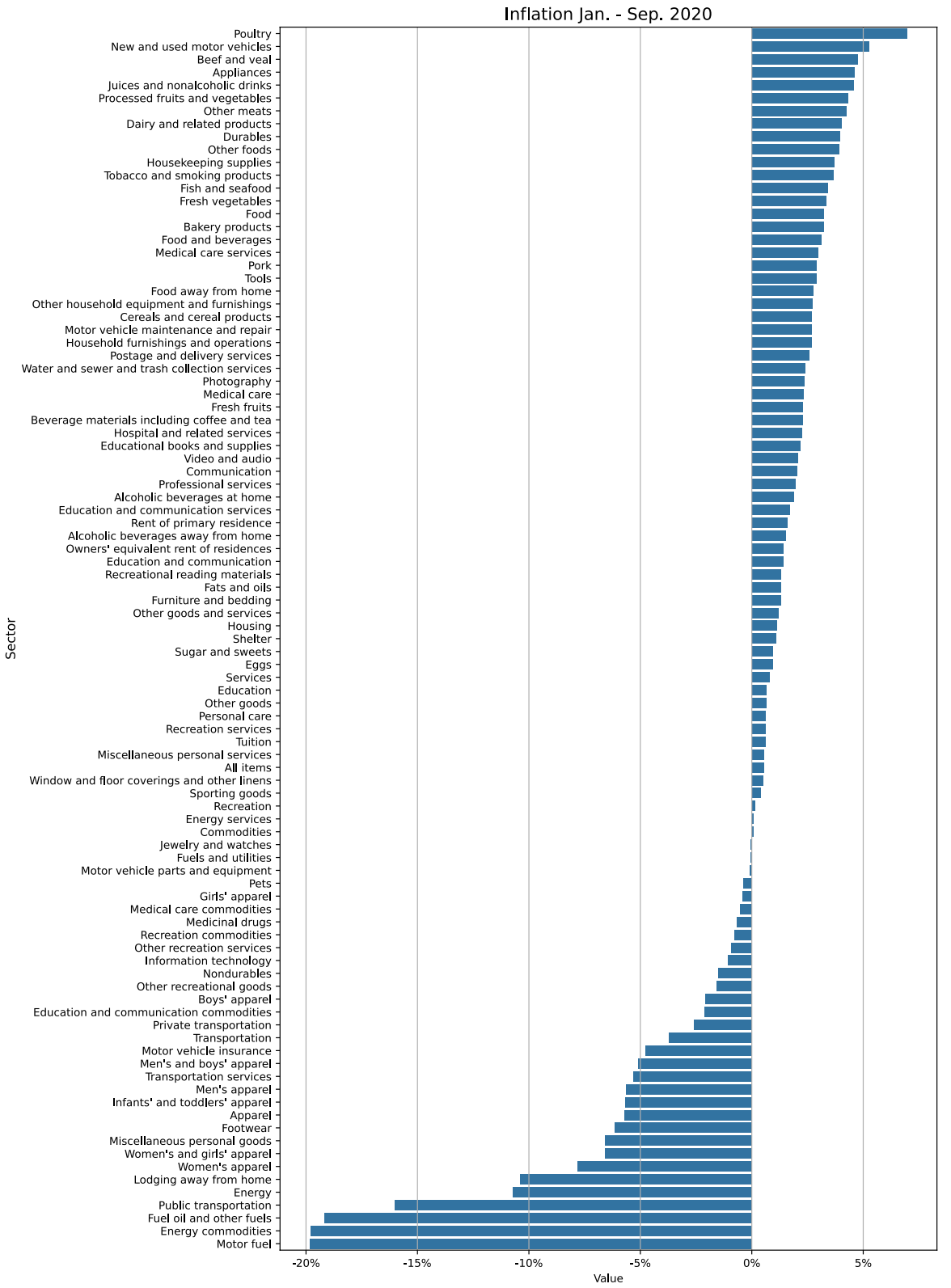

Fig. 3 US Inflation by sector between January and September of 2020

an example; during the pandemic the demand for personal protective equipment, foods, and other essential supplies rose dramatically, which raised the concern of price gouging with both regulators and the general public. 
On the side of regulators, Executive Order 13910 of March 23, 2020, "Preventing Hoarding of Health and Medical Resources To Respond to the Spread of COVID19 " was issued by the USA to deal with the threat of price gouging. Individual states of the USA, evidenced in the laws of King and Spalding (2020), were very active in controlling companies' pricing for products related to the pandemic.

Many State Attorney General Offices created procedures to deal with price gouging complaints. ${ }^{18}$ The purpose of these laws is quite "benevolent"; regulators seek to prevent hoarding and ensure that the prices of essential goods do not increase beyond that which is considered "reasonable or fair." However, in practice, it is not possible to distinguish which part of the price increase is reasonable (e.g., a price increase which generates profits to compensate for the cost of diversification in normal times) and which part is not reasonable (e.g., price increase due to hoarding).

During COVID-19, the companies that had previously diversified their production, and were hence able to keep producing essential products during the pandemic, were not rewarded with higher profit. They were unable to set prices freely and were instead penalized by the increasing litigation risk of anti price gouging enforcement - failing to benefit from prices adjusting to a new equilibrium. As a result, diversifying and preparing for aggregate shocks may not a financially optimal decision for companies in classic market equilibrium models. Theoretically, the problem described above is an inefficient allocation due to market incompleteness. Our model, with individual producers and the fixed-price assumption, reflects this issue.

The general public also paid great attention to price gouging. It was common in social media for people to show images of exorbitant prices of essential goods or to compare the price of essential goods to other products. Examples include the comparison of prices between isopropyl alcohol with a a bottle of champagne, also a convenience store clarifying that the price of toilet paper is not a joke, and another one in which purchase of water are restricted. ${ }^{19}$

When the consumers and law enforcement are so concerned with price increases after a natural disaster, it is reasonable to expect that firms are unable to fully benefit from the scarcity, and may even prefer not to supply than to face the public relations nightmare that would require justifying their selling price.

The examples we discuss here are only in the US, but European countries experienced a similar search for firms violating price gouging laws. See Cary et al. (2020) and UK Competition Authority (2020) for a discussion of the recent law enforcement efforts regarding complains of price abuses in many developed nations.

On the side of the general public, price gouging received immediate attention at the start of the pandemic. Even though the images constitute anecdotal evidence, we can provide evidence on the intensity with which people searched for "price gouging."

\footnotetext{
${ }^{18}$ See Fig. 2.4 in Jiang, Rigobon,Rigobon (2021) working paper version of this paper for images supporting these actions.

${ }^{19}$ See Figs. 2.5 and 2.6 in Jiang, Rigobon, Rigobon (2021) working paper version of this paper. The figure shows images from searching Google on October 5th, 2020 for "price gouging". Many images of products with exorbitant prices are shown in Fig. 2.5, while Fig. 2.6 shows the comparisons of prices made by consumers.
} 
Figure 4 shows the Google search frequencies of topics "Coronavirus" and "Price Gouging" in different regions (USA, UK, and worldwide) as well as different languages (English and Spanish). It is evident that the public's awareness of "price gouging" rises almost simultaneously with awareness of "Coronavirus" itself.

Supply chain allocation is a durable decision. Nevertheless, we identify price inflexibility as a source of fragile supply chain allocation for the following reasons: First, supply chain allocation is durable and unlikely to adapt during disasters on a large scale, which means the supply disruption is generally as long as the disaster itself. Second, when an aggregate shock hits, the anti-price gouging enforcement actions are as long as the supply-side shock. For example, Anderson and Apfel (2020) summarizes many anti-price gouging enforcement actions worldwide from February to July 2020. Third, even if the period of price distortion during a disaster is relatively short compared to normal times, it eliminates companies' essential motivation to diversify production to less competitive locations and prepare for those shocks. In summary, we believe price inflexibility is an important externality when studying aggregate shocks like the global pandemic and many natural disaster events.

\section{Model}

In this section, we present a firm-location-problem model that highlights the vulnerability of the global supply chain to aggregate shocks. It is a simple survival model in which individual firms fail to take into consideration the impact they have on the aggregate - a standard externality argument - and whose decisions change quite substantially once uncertainty is taken into account.

We assume two different forms of organizing the world supply chain. In the first, a multinational asks already established firms (factories) to independently offer the parts required to produce a final product. In this case, the factories decide where to locate themselves. We identify this structure with a global supply chain of Independent Suppliers or the Decentralized economy. The second organization is one in which the multinational allocates its production facilities - which are the subsidiaries of the multinational. We identify this structure as Multinational Subsidiaries or as the Centralized economy.

As said before, a second ingredient in our model is the difference between risk and uncertainty. Optimization under risk produces a policy function that is very different from that derived under uncertainty. Our model is a single firm, partial equilibrium model, which concentrates on the existence and response of the supply chain to aggregate shocks. The COVID-19 pandemic was an obvious aggregate shock. However, natural and environmental disasters become more prevalent, which implies that we need a different approach to the understanding of resilience and robustness of the supply chain. A distinct feature of these shocks is their aggregate nature, but also how uncertain they are; we might know that sea level will be rising, but the extent of the damage has tremendous uncertainty, and the distribution itself is likely to be unknown. 


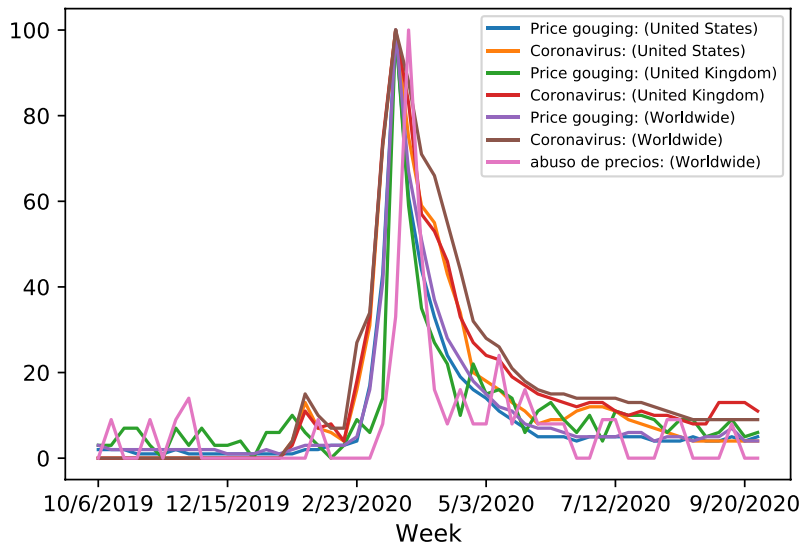

Fig. 4 Google search frequencies of topics "Coronavirus" and "Price Gouging." Numbers are normalized by 100 at maximum values. Data source: https://trends.google.com/trends/

We use both ingredients - the internalization of survival (the externality) and the robust approach (uncertainty) - to rationalize supply chains whose level of diversification is an order of magnitude larger than what we observe in practice.

\subsection{Baseline Model}

A product sold by a multinational is comprised of many "parts," each produced by a factory, and each factory can be located in two different regions. Time occurs in discrete steps, and the discount rate is $\beta$.

Assume there are $N_{t}$ firms at the start of period $t$. Each factory/supplier has a location decision: For simplicity, we will identify the locations as the Mountain and the Valley. Factories choose one of these two locations at time $t$ where they set up production. Each factory only produces one unit of the part, which has a constant cost $c$. Suppliers sell the part to the multinational, who produces the final good. The cost is paid before production takes place.

Production is uncertain. In each period, one of two locations might suffer an aggregate shock with arrival probability $\gamma$. Conditional on such a shock, and before production occurs, all firms in the Mountain or Valley perish with probability $\theta$ or $1-\theta$, respectively. We assume that $\theta>>1 / 2$. In other words, the Mountain is significantly riskier than the Valley. With probability $1-\gamma$, there is no aggregate shock. Production takes place only by the surviving firms, and the multinational produces the final product with the parts it has access to. ${ }^{20}$

At the end of each period, the number of subsidiaries can grow. The growth rate is given by

\footnotetext{
20 The reason behind this assumption is that in the canonical model of complementary inputs (e.g., Kremer (1993)) an idiosyncratic shock has macroeconomic consequences. In our model, we want idiosyncratic shocks to be "harmless" and concentrate on the role of aggregate shocks.
} 


$$
N_{t+1}=A \cdot\left(N_{t}^{s}\right)^{1-\mu}
$$

where $N_{t}^{s}$ denotes the number of firms that have survived the aggregate shock. Notice that this growth process has a fixed point at $N^{*}=A^{1 / \mu}$. In our model, it makes sense to have a decreasing return to scale due to limited resources. This is a distinction with the original model in Lo (2017). The timing is denoted in Fig. 5.

The multinational aggregates parts from all the suppliers and produces a final good. The complexity of the final good depends on the number of parts included. This model has an extremely simple demand side; we assume that the final product's revenue when sold is linear in the number of parts it includes. Furthermore, we add a Survival Constraint to this model by assuming that the firm needs at least 1 part to be able to produce the final product. In other words, $N_{t}^{s} \geq 1$ for the firm to be able to continue operating.

$$
\Pi_{t}= \begin{cases}p N_{t}^{s} & \text { if } N_{t}^{s} \geq 1 \\ 0 & \text { otherwise }\end{cases}
$$

The price per part, $p$, is constant and independent of production and the state of the world. This is equivalent to assuming that all firms are price taker, but it also is capturing the fact that prices rarely move freely after natural disasters - the antiprice gouging laws. This is obviously an extreme assumption, but one that simplifies the exposition. In many countries, there are price gouging regulations that limit the extent to which the pricing system helps ameliorate the supply chain problem. Therefore, the pricing system cannot finance the supply chain reforms required to reestablish production, and instead, other actions (such as time or government subsidies) are required to recover the supply chain. During the COVID-19 pandemic, it has been clear that fairness arguments have dominated the discussion. For example, see Executive Order 13910 of March 23, 2020, Preventing Hoarding of Health and Medical Resources To Respond to the Spread of COVID-19, or King and Spalding (2020) for a list of price gouging laws in the USA. A more detailed discussion of price gouging during COVID-19 is given earlier in Sect. 2.3.

Two important aspects of the price assumption are worth highlighting. First, we are assuming a very extreme form of anti-price gouging - prices are completely fixed. In our model, the anti-price gouging behavior is quite important for our results. If prices cannot adjust after a natural disaster, there is no way of compensating the suppliers that locate themselves in the mountain. On the other hand, if firms face a standard demand satisfying the Inada conditions, then all suppliers can be compensated when locating themselves in the mountain. In fact, it is optimal to make the expected value of investing in the mountain equal to investing in the valley. The assumption of anti-price gouging laws, however, is not unreasonable. First, they are observed in practice. Second, as argued in Dworczak et al. (2020), anti-price gouging laws can be socially optimal in the presence of income inequality and other inefficiencies.

The second aspect worth highlighting is that the price gouging is as long as the investment horizon. This is also an extreme assumption that allows us to characterize the solution. In our case, the investment horizon is one period (after 
which the suppliers can relocate without cost). Future research should include the possibility that there is stickiness in the location decision to study the implications of price freezes shorter than the investment horizon.

The fact that inflation is found in some of the sectors could be misconstrued as a rejection of the price gauging assumption. That is not necessarily the case. If prices are not allowed to increase to the market clearing price there is scarcity in the market and inflation at the same time. For most of the products highlighted here, inflation, and rationing and excess demand indeed existed.

Denote $\psi_{t}$ the proportion of firms that are located in the Valley. The evolution of firms is given by

$$
N_{t+1}=\left\{\begin{array}{lll}
A \cdot\left(N_{t}\right)^{1-\mu} & \text { w/p } & (1-\gamma) \\
A \cdot\left(\psi_{t} N_{t}\right)^{1-\mu} & \text { w/p } & \gamma \theta \\
A \cdot\left(\left(1-\psi_{t}\right) N_{t}\right)^{1-\mu} & \text { w/p } & \gamma(1-\theta)
\end{array}\right.
$$

where the top realization occurs when there is no aggregate shock, and the second (third, respectively) one is when the aggregate shock hits the Mountain (Valley, respectively). The growth of the firms has two components: multiplicative and exponential. As can be seen, the growth of suppliers depends on the total number of surviving suppliers in the world. We assume that the new suppliers are distributed according to the existing number of surviving firms in each location, but that the growth rate depends on the total number of existing firms. This assumption in the basic model is innocuous, but it is essential if the model is extended to introduce adjustment costs - or switching costs. We leave this interesting application for future research.

\subsubsection{Independent Producers}

In the independent producers setting, the suppliers decide their location individually, and then the multinational contracts with the firms. We assume that all the revenue from the multinational is transferred to the suppliers - i.e., the multinational has zero profits. The total revenue is equally shared among the surviving suppliers.

Suppliers are small and they do not take into account the impact their decision has on the decision of the location of others $\left(\psi_{t}\right)$. As we mentioned before, there is no cost of switching between locations. Therefore, the suppliers are solving a static problem - the continuation value is exactly the same for all firms. Firms are maximizing the expected value of Mountain versus Valley and given our assumptions Valley dominates for all firms. Then, the value at time $t$ of locating in the Valley or the Mountain is given by

$$
\begin{gathered}
V_{t}^{v}=((1-\gamma)+\gamma \theta) p-c+\frac{1}{1+\beta}((1-\gamma)+\gamma \theta) V_{t+1} \\
V_{t}^{m}=((1-\gamma)+\gamma(1-\theta)) p-c+\frac{1}{1+\beta}((1-\gamma)+\gamma(1-\theta)) V_{t+1} .
\end{gathered}
$$




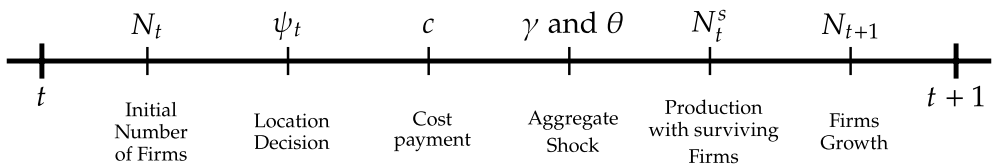

Fig. 5 Model timing

The continuation value for each supplier, conditional on having survived the aggregate shock, is independent of the location. This is a feature of the zero cost of relocation. Therefore, the value of locating in the Valley is always larger than the value of locating in the Mountain. Formally,

$$
V_{t}^{v}-V_{t}^{m}=\gamma(2 \theta-1)\left(p+\frac{1}{1+\beta} V_{t+1}\right)>0
$$

for $\theta>1 / 2$, and hence $\psi_{t}=1$.

\subsubsection{Multinational Subsidiaries}

Assume now that the multinational has all the decision power and it allocates the production units. Two aspects now matter for the multinational firm that were not relevant for the independent suppliers: The multinational takes into account the distribution of firms, and it takes into account the expected value of continuation in all states of the world.

The problem of the multinational firm can be written as follows:

$$
V\left(N_{t}\right)=\max _{\psi_{t}}\left\{\left[\begin{array}{l}
(1-\gamma) \cdot\left(p N_{t}+\frac{1}{1+\beta} V\left(A \cdot\left(N_{t}\right)^{1-\mu}\right)\right) \\
+\gamma \theta \cdot\left(p \psi_{t} N_{t}+\frac{1}{1+\beta} V\left(A \cdot\left(\psi_{t} N_{t}\right)^{1-\mu}\right)\right) \\
+\gamma(1-\theta) \cdot\left(p\left(1-\psi_{t}\right) N_{t}+\frac{1}{1+\beta} V\left(A \cdot\left(\left(1-\psi_{t}\right) N_{t}\right)^{1-\mu}\right)\right)
\end{array}\right]-c N_{t}\right\}
$$

where

$$
\lim _{N \rightarrow 1^{-}} V(N)=0
$$

is the value matching constraint.

As before, the top line represents the value when the aggregate shock does not occur, and the second (third, respectively) when the aggregate shock hits the Mountain (Valley, respectively). Although the cost is the same $c N_{t}$, the revenue depends on the number of surviving firms. Recall that the cost of production is paid irrespectively of the aggregate shock.

The first-order condition (FOC) with respect to $\psi_{t}$, after simplifying, is

$$
(2 \theta-1) p=A(1-\mu) \frac{N_{t}^{-\mu}}{1+\beta}\left\{(1-\theta)\left(1-\psi_{t}\right)^{-\mu} V^{\prime}\left(A\left(\left(1-\psi_{t}\right) N_{t}\right)^{1-\mu}\right)-\theta \psi_{t}^{-\mu} V^{\prime}\left(A\left(\psi_{t} N_{t}\right)^{1-\mu}\right)\right\} .
$$


We simulate the discrete time version of the model to characterize the solution. ${ }^{21}$ The parameters used in the simulation are: $\beta=0.02, \gamma=0.2, \theta=0.6, \mu=0.5$, $A=5, p_{m}=p_{v}=1$ and $c_{m}=c_{v}=0.5$.

In terms of the number of suppliers in equilibrium, the choice of $\mu=0.5$ implies a fixed point of $N_{t}=25$, in the absence of aggregate shocks. We initialize all simulations in this fixed point.

In Fig. 6, we present the proportion of firms in the Valley as a function of the total number of suppliers (horizontal axis). The orange line represents the decentralized allocation - the individual rationality solution. The blue line indicates the probability matching solution for survival. Finally, The green line indicates the optimal solution of the multinational.

The multinational has a trade-off between instantaneous profits (what the individual suppliers maximize) and the probability of survival. The right panel of Fig. 6 is a closer view of the left panel, but concentrating on relatively small $N$.

As shown in Fig. 6, the multinational's optimal $\psi$ is a function of the number of production units $N_{t}$ and has three distinct phases. In the first phase, when $N_{t} \in[1,2)$, the multinational's optimal choice is a corner solution, which coincides with individuals' optimum. This occurs because when $N_{t}<2$, losing one unit will discontinue the multinational's operation. Hence, there is no way to ensure survival and to realize the benefit of continuation value. In the second phase, when $N_{t} \in[2,3)$, the multinational will allocate exactly one production unit to the Mountain to take advantage of the continuation value. As a result, the optimal allocation is given by $\psi^{*}=1-1 / N_{t}$. In the third phase, when $N_{t} \geq 3$, the optimal $\psi$ is a concave increasing function of $N_{t}$. It is increasing because, with guaranteed survival, it is optimal to allocate a greater percentage of production units to the Valley to maximize profit. It is concave because the function $\psi^{*}\left(N_{t}\right)$ asymptotically approaches a constant $<1$.

The value function of the multinational, with the optimal $\psi$, is presented in Fig. 7. The concavity of the value function comes from the concavity of the growth function of the suppliers and also from the value matching constraint. If the suppliers grow at a constant rate, the value function would be linear with respect to the number of suppliers - and therefore, even the solution of the multinational would be at a corner.

The value function has two discontinuities points at $N_{t}=1$ and $N_{t}=2$. The discontinuity at $N_{t}=1$ is trivial due to the constraint that $V\left(N_{t}\right)=0, \forall N_{t}<1$. On the other hand, the discontinuity at $N_{t}=2$ has an important implication about continuation value. When the number of production units is $<2$, the multinational firm cannot ensure survival. When the number of production units is $\geq 2$, the multinational can allocate one production unit on the Mountain to ensure survival. This ensured survival creates a continuation value for the multinational, which is responsible for the jump of value function at $N_{t}=2$.

$\overline{21}$ We present the derivation of a continuous-time version of the model in Appendix A. 


\subsection{Probability Matching}

As shown in Fig. 6, the optimal proportion of firms in the Valley varies with the number of suppliers. It is interesting to compare the effectiveness of the optimal firm allocation with respect to a naive strategy - a constant psi independent of the number of firms. For instance, assuming the probability matching strategy is adopted, the value function of the multinational with constant $\psi=0.6$ is presented in Fig. 8.

Apart from the trivial discontinuity at $N_{t}=1$, the value function has two other discontinuous points at $N_{t}=5 / 3$ and $N_{t}=2.5$. Below $5 / 3$, the constant $\psi=0.6$ does not place a single production unit in either location, and the multinational fails when any aggregate shock occurs. As a result, the discontinuity at 5/3 represents the continuation value of firms in the Valley. On the other hand, the discontinuity at $N_{t}=2.5$ represents the continuation value of firms in the Mountain. When the number of available production units is $<2.5$, the multinational places fewer than one unit in the Mountain and will not survive an aggregate shock to the Valley. However, when the number of production units is $\geq 2.5$, the multinational can allocate at least one production unit on the Mountain, thereby ensuring survival. The jump of the value function at $N_{t}=2.5$ reflects this guaranteed survival.

The difference between the value function using the optimal strategy, and the value function following the probability matching strategy is small. We compare the optimal-strategy value function with the probability-matching value function (when $\psi$ is constant and equal to 0.60). Figure 9 shows the percentage increase in the value function when the firm switches between probability matching to optimal.

The $x$-axis is the number of firms on a logarithmic scale, and for comparison purposes, we concentrated on $N_{t}>3$. The discrete jumps in the value function for smaller $N_{t}$ swamp any possible comparison outside that region. On the $y$-axis is the percentage difference between the two value functions.

The relationship, as expected, is increasing. The reason is that the optimal $\psi$ increases with the number of surviving firms; therefore, the loss incurred by fixing it at 0.60 is also increasing. Having said this, notice that the magnitudes are small: between 1 and $2 \%$.

One interesting question to ask is how the probability of survival is affected by different possible allocation strategies by the multinational. Recall that Fig. 6 indicates that the optimal proportion of firms in the Valley is a function of the total number of suppliers that exist. However, we here study a simple, naive allocation strategy in the spirit of probability matching models. For instance, assume the multinational chooses a fixed proportion of suppliers in the Valley regardless of the total number of suppliers that exist.

In Fig. 10, we present the probability of survival for various fixed values of $\psi$ over different horizons. We define the probability of survival as one minus the probability that the number of suppliers is smaller than 1 for any time step within the horizon, and initialize simulations with the same parameters as above.

For large time horizons, the probability is either one or zero; interestingly, the breakpoints include the probability matching proportion $(\psi=0.6)$. 

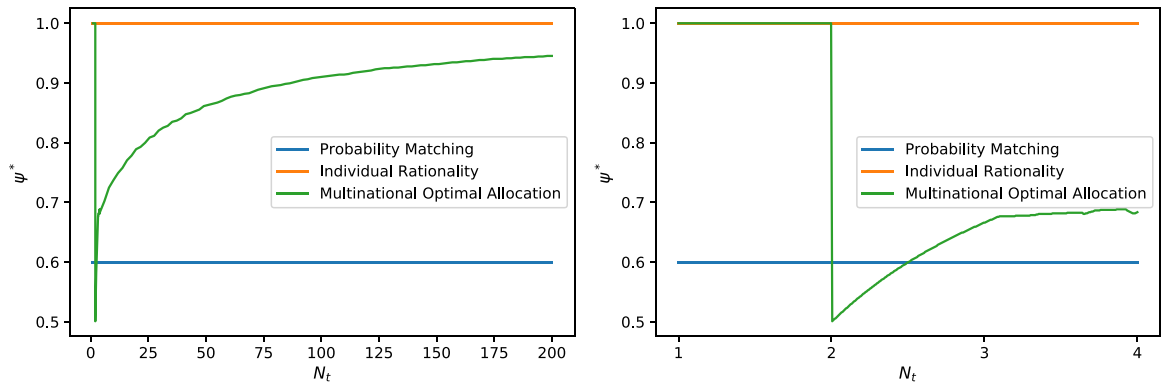

Fig. 6 Optimal $\psi^{*}$ as a function of $N_{t}$
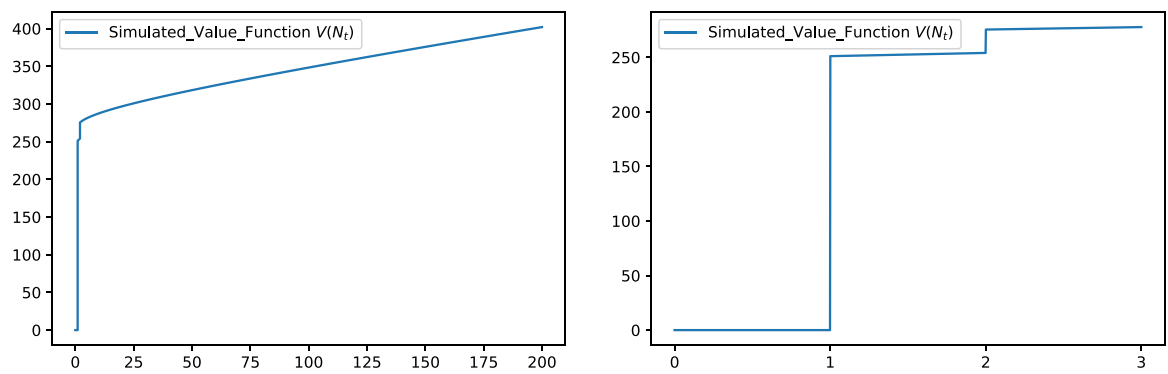

Fig. 7 Value function $V\left(N_{t}\right)$ with optimal $\psi$

\subsection{Implications}

This model presents a simple contrast between three possible strategies: the decentralized allocation in which firms do not take into account the survival probability of the multinational, the centralized allocation in which the multinational internalizes the decision, and the behavioral response that would use simple probability matching heuristics concentrating on the maximization of the probability of survival.

The behavioral finance literature points out many cases in which individuals will tend to chose the third strategy. In our model, indeed, such a strategy will guarantee the survival of the multinational. However, it is inefficient. A dynamic allocation increases profits, for example, and also guarantees the survival of the firm in equilibrium.

Many questions arise from this framework that we explore further in this paper and some that are left for future research.

First, how can the probability matching behavior be rationalized in this setting? As shown in Fig. 6, the optimal allocation in the Valley is an increasing function of the number of surviving firms - after $N_{t}>2$. So, the optimal solution is an internal solution, and it is dependent on the number of firms. As we discussed before, some jumps happen at small numbers, which are the result of the constraint at which the multinational shuts down. Probability matching implies a constant proportion of firms regardless of the number of surviving firms, which contradicts this feature of the multinational's optimal allocation. In Sect. 4, we will introduce uncertainty and 

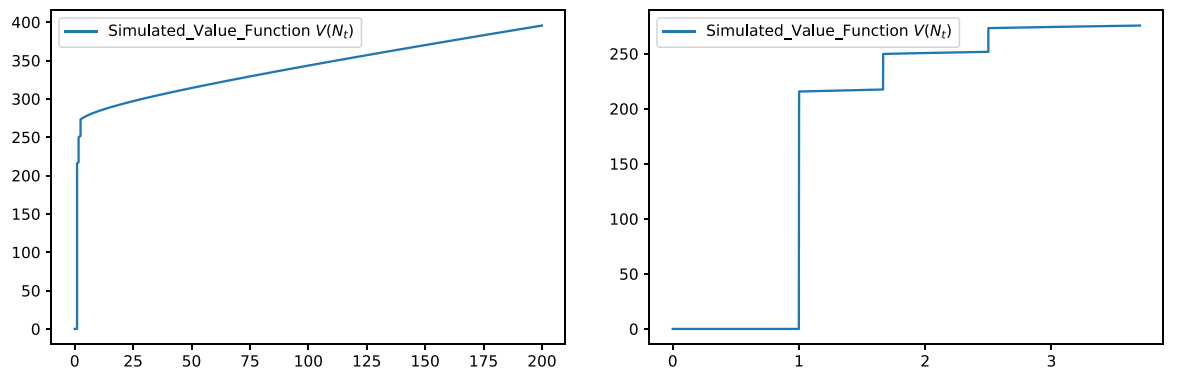

Fig. 8 Value function $V\left(N_{t}\right)$ with constant $\psi=0.6$

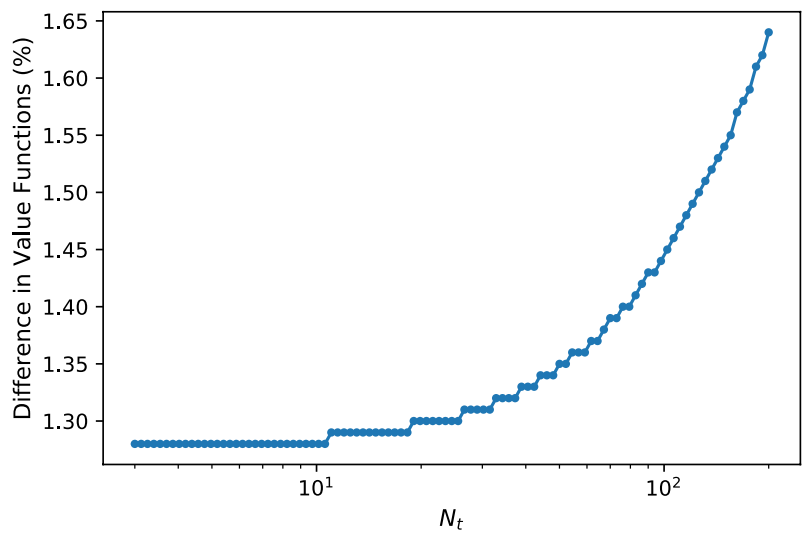

Fig. 9 Difference between value function $V\left(N_{t}\right)$ with optimal $\psi$ and value function with constant $\psi=0.6$

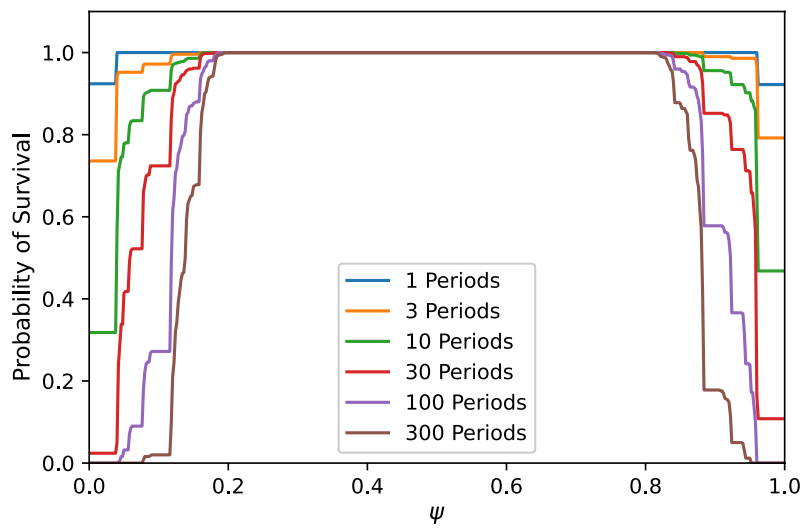

Fig. 10 Probability of survival 
show how the robust optimal response is indeed very close in its spirit to the probability matching.

Second, given the externality, is there something that a government could do such that the decentralized economy could reproduce the centralized allocation? The answer to this question is usually yes, and it either requires taxes or subsidies. We study this point in Sect. 5. We show that in the context of differences in prices, there exists a governmental policy in which the decentralized economy achieves the centralized outcome - or at least - the firms are indifferent between locating in the Mountain versus the Valley, so the centralized allocation is available. The price or cost differences can be interpreted as an ex-ante tax or subsidy to the allocation of a firm in a particular destination.

Although trivial, it is worth highlighting that if prices are allowed to adjust, the decentralized allocation will replicate the centralized one. In our model, prices are not allowed to change, and therefore, it is impossible to compensate the firms in the Mountain when a shock to the Valley has taken place. If the prices were to adjust, then once an aggregate shock takes place, the revenues of the surviving suppliers would increase. Moreover, because there are fewer firms in the Mountain, the price increase when a shock to the Valley takes place would increase the price of parts more than when the shock occurred in the Mountain. Because survival is very important, any usual demand function - CES for example - implies that the expected value of firms in the Mountain and the Valley are equalized. Under those circumstances, the decentralized economy reproduces the centralized one. The assumption of prices NOT adjusting is crucial. We do believe it is a reasonable assumption when aggregate shocks occur, justified through the prevention of price gouging.

Third, a simplifying assumption in our model is that the growth of firms is related to the total number of surviving firms regardless of where the firms were located. Also, we are assuming that there is no cost of reallocation. These are simplifying, but unreasonable assumptions. Further research should look into the implications when the growth of firms is specific to the location, and there are adjustment costs. We leave this extension to future research.

Finally, our supply chain structure is extremely simple. In reality, supply chains look like complex networks. ${ }^{22}$ Future research should look at the implications of robustness in a more complex structure.

\section{The Nominal and the Robust Models}

The model in the previous section only deals with risk. In this section, we explore the implication of adding uncertainty into the model. In particular, we will assume the probability of the aggregate shock in the Valley $(\theta)$ is uncertain. As has been said before, this section shows that the optimal robust strategy is exactly in the spirit of probability matching: a constant proportion regardless of the number of firms that exist.

${ }^{22}$ See Yeaple (2003).

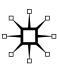


We study two cases: In the first, we consider a risky $\theta$. Here, we assume that $\theta$ is uniformly distributed in $[\bar{\theta}-\Delta, \bar{\theta}+\Delta]$. Due to the linearity of the value function with respect to $\theta$, we show that the optimal choices for both the individual producers and the multinationals are the same as the baseline case. Though the result is trivial in this case, it allows us to set up the comparison with our second case, where we assume model uncertainty: $\theta$ can be any value between $[\bar{\theta}-\Delta, \bar{\theta}+\Delta]$ and agents deploy a robust decision rule by solving a minimax problem.

\subsection{Risk: The Nominal Model}

Let us assume that $\theta \in[\bar{\theta}-\Delta, \bar{\theta}+\Delta]$, where $\Delta$ is small enough to guarantee that the support of $\theta$ is contained in $[0,1]$. We assume that the distribution is uniform and known by all agents. This setting is identified in our discussion as the nominal model. We will continue to assume that the Mountain is riskier; therefore, $\bar{\theta}>1 / 2$. Because individual suppliers are risk-neutral and the aggregate shock enters linearly, the decentralized equilibrium is identical: All the suppliers choose to locate in the Valley.

Similarly for the multinational, because $\theta$ enters linearly to the value function, the profit maximization problem and its solution is unchanged. More specifically,

$$
\left.\begin{array}{rl}
V\left(N_{t}\right) & =\max _{\psi_{t}\left(N_{t}\right)} \int_{\bar{\theta}-\Delta}^{\bar{\theta}+\Delta}\left\{\begin{array}{l}
(1-\gamma) \cdot\left(p N_{t}+\frac{1}{1+\beta} V\left(A \cdot\left(N_{t}\right)^{1-\mu}\right)\right) \\
+\gamma(\theta) \cdot\left(p \psi_{t} N_{t}+\frac{1}{1+\beta} V\left(A \cdot\left(\psi_{t} N_{t}\right)^{1-\mu}\right)\right) \\
+\gamma(1-\theta) \cdot\left(p\left(1-\psi_{t}\right) N_{t}+\frac{1}{1+\beta} V\left(A \cdot\left(\left(1-\psi_{t}\right) N_{t}\right)^{1-\mu}\right)\right)
\end{array}\right]-c N_{t}
\end{array}\right\} d \theta
$$

Therefore, under the assumption of risk the solutions of the decentralized and decentralized economy are identical to the baseline model. Of course, this is a feature of the assumptions we have chosen to make and where the parameter risk was introduced. We have made these choices for simplicity.

\subsection{Uncertainty: The Robust Model}

The second case we study is the case of uncertainty in the sense of robust control. Assume that all agents know that $\theta \in[\bar{\theta}-\Delta, \bar{\theta}+\Delta]$, but they do not know the distribution.

Optimal control implies that the optimization maximizes the worst possible case. For individual producers, the values in the Valley and the Mountain are

$$
\begin{aligned}
V_{t}^{v} & =\min _{\delta \in[-\Delta, \Delta]}((1-\gamma)+\gamma(\bar{\theta}+\delta)) p-c+\frac{1}{1+\beta}((1-\gamma)+\gamma(\bar{\theta}+\delta)) V_{t+1} \\
V_{t}^{m} & =\min _{\delta \in[-\Delta, \Delta]}((1-\gamma)+\gamma(1-\bar{\theta}-\delta)) p-c+\frac{1}{1+\beta}((1-\gamma)+\gamma(1-\bar{\theta}-\delta)) V_{t+1} .
\end{aligned}
$$


Because nature will choose a value of $\Delta$ that minimize producers' value, the worstcase scenario for the Valley is when $\delta=-\Delta$, and the worst-case scenario for the Mountain is when $\delta=\Delta$. The difference in value between the Valley and Mountain is given by

$$
V_{t}^{v}-V_{t}^{m}=\gamma(2 \bar{\theta}-1)\left(p+\frac{1}{1+\beta} V_{t+1}\right)>0
$$

for $\bar{\theta}>1 / 2$. Note this is identical to the baseline case [Eq. (3.4)] in Sect. 3. The worst case for each individual firm still implies that the worst case in the Valley is better than the worst case in the Mountain.

The problem of the multinational firm can be written as follows:

$$
V\left(N_{t}\right)=\max _{\psi_{t}\left(N_{t}\right)} \min _{\delta \in[-\Delta, \Delta]}\left\{\left[\begin{array}{l}
(1-\gamma) \cdot\left(p N_{t}+\frac{1}{1+\beta} V\left(A \cdot\left(N_{t}\right)^{1-\mu}\right)\right) \\
+\gamma(\bar{\theta}+\delta) \cdot\left(p \psi_{t} N_{t}+\frac{1}{1+\beta} V\left(A \cdot\left(\psi_{t} N_{t}\right)^{1-\mu}\right)\right) \\
+\gamma(1-\bar{\theta}-\delta) \cdot\left(p\left(1-\psi_{t}\right) N_{t}+\frac{1}{1+\beta} V\left(A \cdot\left(\left(1-\psi_{t}\right) N_{t}\right)^{1-\mu}\right)\right)
\end{array}\right]-c N_{t}\right\}
$$

subject to

$$
\lim _{N \rightarrow 1^{-}} V(N)=0 .
$$

The above value function has the following characteristics: First, given any fixed $\delta$, the value function is upper semi-continuous and concave in $\psi$, for all $N_{t} \geq 2$. For $N_{t}<2$, there is a unique corner solution. Second, given any fixed $\psi$, the value function is linear (therefore continuous and convex) in $\delta$. Finally, $\psi \in[0,1]$ and $\delta \in[-\Delta, \Delta]$ are chosen from compact sets.

As a result, according to Sion's minimax theorem (Sion et al. 1958), the maximization and minimization are interchangeable, and the minimax problem has at least one solution.

The optimal $\delta$ (meaning the choice that produces the worst possible case for the multinational) is given by

$$
\delta^{*}=\left\{\begin{array}{ll}
-\Delta & \text { if } \bar{\theta}-\Delta>1 / 2 \\
-\bar{\theta}+1 / 2 & \text { if } \bar{\theta}-\Delta<=1 / 2
\end{array} .\right.
$$

This then implies that the multinational's optimal response is the $\psi$ from Fig. 6, but where the shock probability is given by $\theta=\bar{\theta}+\delta^{*}$.

\subsection{Efficiency vs. Robustness}

It may seem too conservative to always considering the worst-case scenario, especially for multinationals trying to maximize profit. Even though the worst-case scenario is known to be $\delta=-\Delta$ for small enough $\Delta$, this scenario may not be considered by the agents in the system who seek efficiency. Naturally, an efficiency versus robustness trade-off emerges.

Figure 11 shows the comparison of the case of the nominal and worst-case models. The blue line represents the value function for the nominal model and the orange 
the value function for the robust model. The simulations are constructed assuming that the uncertainty parameter $\Delta=0.05$ and that $\bar{\theta}=0.6$. So, the range for $\theta$ is between $[.55, .65]$. The nominal model optimizes as if $\delta=0$, and we plot what the realized value function for $\delta<0$ instead being zero. In other words, when $\delta=0$, the blue line reaches the maximum because the real value of theta is exactly the one used by the multinational to optimize. On the other extreme (left), when the value of $\delta=-0.05$ the multinational makes choices thinking that the relative shock parameter is $\bar{\theta}$ when it actually is $\bar{\theta}-0.05$. Therefore, the nominal value function is subject to potential losses.

The orange line is the robust model. Given the assumption of the bounded range, we know that the multinational assumes that the $\theta=\bar{\theta}-0.05$. In this case, notice that the orange line is flatter, and the worst-case is better than when the nominal model chooses. In fact, the robust model is optimal when $\delta=-0.05$.

Figure 12 depicts the case when $\Delta=0.15$. In this case, the size of the uncertainty is large enough that the case of $\theta=0.5$ is in the support. According to Eq. (4.2), the robust approach assumes that $\theta=0.5$.

Notice that the blue line - the nominal model - behaves similarly as in the previous case, except that a larger range implies bigger potential losses. Again, in the extreme left, the multinational assumes that $\theta=0.6$ when it actually is 0.45 . In contrast, the orange line assumes a $\theta=0.5$ and produces a totally flat value function.

The intuition behind this result is simple. The robust allocation of suppliers is to set half in the mountain and half in the valley. This implies that in the presence of an aggregate shock - independently where it occurs - half of the suppliers disappear. The flows and costs are identical. Therefore, the expected value is independent of the true " $\theta$."

These two figures highlight the implications of applying robustness to a decision problem. Robustness is needed when the agents do not know the distribution of the shock they are facing, and therefore need to prepare for the worst. Robustness, then, serves to find a policy that reduces the differences over all possible states of nature. In the limit, the most robust action is one in which the outcomes are identical in all states of nature (as shown in Fig. 12).

\subsection{Discussion}

The results in our model need two ingredients: robustness and a centralized decision maker that internalizes survival probabilities. Table 1 summarizes the relationships between the modeling choices and the characteristics of the policy function.

When the economy is populated with decentralized decision makers, the optimal policy choices are independent of the nature of the shock. In other words, individual suppliers will choose a corner solution (e.g., locating exclusively in the Valley) irrespectively of whether they are facing risk or uncertainty. A centralized decision maker, on the other hand, tends to prefer internal solutions. When they face risk, the optimal allocation of firms is an increasing function of the number of firms. It is 


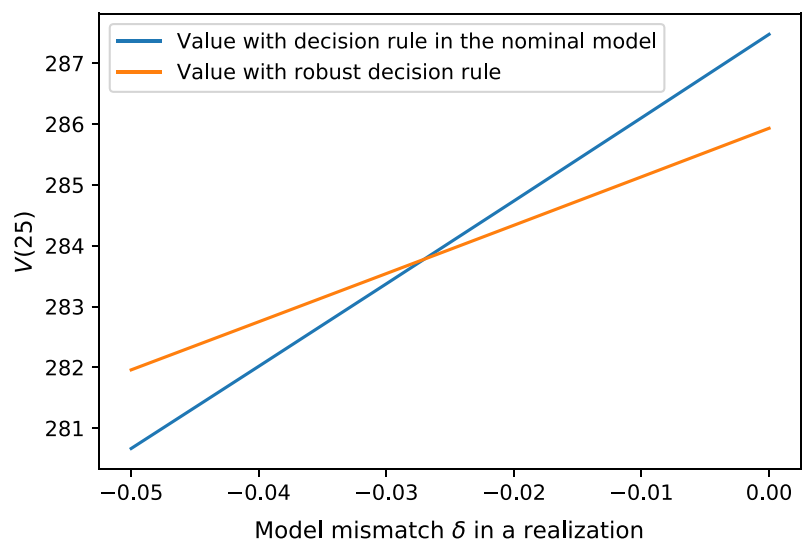

(a) $\Delta=0.05$

Fig. 11 Efficiency versus robustness. $\Delta=0.05$. Efficiency is represented by the value in nominal model, and robustness is represented by the value in worse-case model. The number of firms $N_{t}$ is 25

when both uncertainty and centralization are present that the solution is an internal and fixed ratio, very much in the spirit of probability matching.

This result has important implications for the supply chain. In our model, it does not matter how bad the Mountain is relative to the Valley, there is a level of uncertainty for which the multinational allocates half the firms in the Mountain. A robust supply chain is one in which the survival probability is maximized, and where there will be production even in the worst of circumstances. Of course, this is a result that depends on the underlying assumptions of the model, but the intuition should be easy to extend to more realistic circumstances: If the supply chains in the world would have been prepared to supply goods in the worst possible circumstance, then the COVID-19 shock should have produced zero stock-outs. A supply chain that deals with risk but optimizes using the "expected" value is found to be ill-prepared to handle an aggregate shock of the magnitude implied by COVID-19.

Finally, robustness is often compared to the solution of a model with large risk aversion. In some applications, that is indeed the case. In our model, robustness changes the nature of the solution - in fact, the optimal allocation is independent of the number of firms, and the allocation in Mountain and Valley is symmetric. It is common in economics to equate robust approaches to greater risk aversion, which itself leads to higher incentives for diversification. Again, that is not the case in our model. The result we highlight, that implicitly rationalizes probability matching, cannot be achieved with infinite risk aversion. 


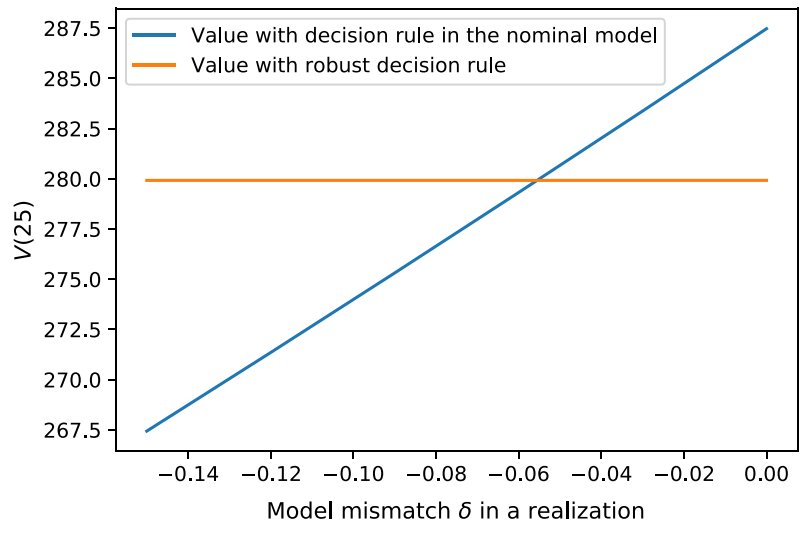

(b) $\Delta=0.15$

Fig. 12 Efficiency versus robustness. $\Delta=0.15$. Efficiency is represented by the value in nominal model, and robustness is represented by the value in worse-case model. The number of firms $N_{t}$ is 25

Table 1 Relationship between modeling choices and characteristics of the policy function

\begin{tabular}{lll}
\hline & Risk & Uncertainty \\
\hline Decentralized & Corner & Corner \\
& Solution & Solution \\
& Valley & Valley \\
Centralized & Internal & Probability \\
& Solution & Matching \\
& $\psi\left(N_{t}\right)$ & $\psi^{\prime}\left(N_{t}\right)=0$ \\
\hline
\end{tabular}

\section{Price and Cost Differences}

Up to now, we have not allowed prices to change depending on the state of the world. This is clearly a simplification that has allowed us to characterize the solution of the model and study the price gouging case. This section, in practice, relaxes the price gouging assumption. ${ }^{23}$ The conclusion so far is that even when prices do not adjust - making the decision to locate the suppliers in the Mountain a less profitable decision - the values of continuation and robustness are enough for the multinational to allocate firms in the Mountain. In this section, we study the implications of allowing prices and costs in the two locations to be different.

\subsection{Model}

We assume that there are heterogeneous costs $c_{v} \neq c_{m}$ and prices $p_{v} \neq p_{m}$ in the two locations. We use this model to address many different questions. First, can

\footnotetext{
${ }^{23}$ See Sect. 2.3 for the justification.
} 
the government define an intervention (either reducing the cost of the Mountain, or increasing its price) for which the decentralized economy achieves the social optimum - even in the case of uncertainty? Second, what is the profit margin of the Mountain at which the robust control strategy ceases to diversify the supply chain? In other words, when is robustness undesirable?

The value functions for the individual suppliers are given by

$$
\begin{gathered}
V_{t}^{v}=((1-\gamma)+\gamma \theta) p_{v}-c_{v}+\frac{1}{1+\beta}((1-\gamma)+\gamma \theta) V_{t+1} \\
V_{t}^{m}=((1-\gamma)+\gamma(1-\theta)) p_{m}-c_{m}+\frac{1}{1+\beta}((1-\gamma)+\gamma(1-\theta)) V_{t+1} .
\end{gathered}
$$

The continuation values still are identical in each of the two locations because there is no cost of relocation of suppliers. The difference between the two locations is given by

$$
V_{t}^{v}-V_{t}^{m}=\left(((1-\gamma)+\gamma \theta) p_{v}-c_{v}\right)-\left(((1-\gamma)+\gamma(1-\theta)) p_{m}-c_{m}\right)+\gamma(2 \theta-1)\left(\frac{1}{1+\beta} V_{t+1}\right) .
$$

There is an expected markup in the Mountain larger than the markup at the Valley at which the firms are indifferent in their location. Intuitively, it is not enough for the markups of the Mountain and Valley to be the same. We need to compensate individuals going to the Mountain for their lower probability of survival. Therefore, given $p_{v}, c_{v}$, and $c_{m}$, there exists a cutoff $p_{m}^{*}$ at which $V_{t}^{v}=V_{t}^{m}=V_{t+1}$. Substituting in Eqs. (5.1) and (5.2), the transition occurs when

$$
\frac{(1-\gamma+\gamma \theta) p_{v}-c_{v}}{1-\frac{1}{1+\beta}(1-\gamma+\gamma \theta)}=\frac{(1-\gamma+\gamma(1-\theta)) p_{m}^{*}-c_{m}}{1-\frac{1}{1+\beta}(1-\gamma+\gamma(1-\theta))}
$$

Given the parameters of our simulation, $p_{m}^{*} \approx 1.24$. Then, for any $p_{m}<p_{m}^{*}$ all individual firms locate in the Valley, and for $p_{v}>p_{m}^{*}$, all locate in the Mountain. The intuition of Eq. (5.4) is simple; it states that the expected markups adjusted by the survival probabilities need to be equated in the two locations.

In this case, the individual allocation implies multiple equilibria due to the indifference between the two locations. Below that markup, the dominant strategy is to locate in the Valley, and above it, the optimal decision is to locate in the Mountain. We compare this solution to the one chosen by the multinational in the exact same setting.

The problem of the multinational firm can be written as: 


$$
\left.\begin{array}{rl}
V\left(N_{t}\right)=\max _{\psi_{t}}\left\{\left[\begin{array}{l}
(1-\gamma)\left(\left(p_{v} \psi_{t}+p_{m}\left(1-\psi_{t}\right)\right) N_{t}+\frac{1}{1+\beta} V\left(A \cdot\left(N_{t}\right)^{1-\mu}\right)\right) \\
+\gamma \theta\left(p_{v} \psi_{t} N_{t}+\frac{1}{1+\beta} V\left(A \cdot\left(\psi_{t} N_{t}\right)^{1-\mu}\right)\right) \\
+\gamma(1-\theta)\left(p_{m}\left(1-\psi_{t}\right) N_{t}+\frac{1}{1+\beta} V\left(A \cdot\left(\left(1-\psi_{t}\right) N_{t}\right)^{1-\mu}\right)\right)
\end{array}\right]\right. \\
\quad-\left(c_{v} \psi_{t}+c_{m}\left(1-\psi_{t}\right)\right) N_{t}
\end{array}\right\}
$$

subject to the same boundary condition we have imposed before:

$$
\lim _{N \rightarrow 1^{-}} V(N)=0 .
$$

The instantaneous profits are linear in prices and costs, so we have decided to keep costs constant and only change the Mountain's price $\left(p_{m}\right)$ in our simulations. Our first result studies how the multinational's optimal policy $\psi^{*}(N)$ changes with the Mountain's price $p_{m}$.

In Fig. 13, we present two panels. The left panel shows the optimal allocation for different number of suppliers, and the panel on the right just zooms into the case when there are few suppliers available. Each colored line indicates a different price level, and prices in the Mountain were varied in the range [0.5, 2.0].

As in the baseline model, when there are two firms the multinational allocates one in each location to ensure survival. We decided to start the figure at that point because nothing particularly new occurs for $N_{t}=1$. As $N_{t}$ increases, the multinational allocates firms depending on the prices and the number of available suppliers.

When the prices are low, the optimal allocation is biased toward the Valley, and when the prices are high, the allocation is biased toward the Mountain. Interestingly, there is a price at which the allocation is virtually flat.

Figure 14 shows the optimal allocation in the Valley for a given $N$, but different values of $p_{m}$. The plot has been drawn for $N_{t}=10$.

The multinational transitions smoothly between extreme values of $\psi^{*}$ as the price of the Mountain varies, but the decentralized equilibrium instantaneously shifts at a critical value of $p_{m}^{*} \approx 1.24$. This phase transition from $\psi^{*}=0$ to $\psi^{*}=1$ occurs when the values of the Mountain and Valley given by Eq. (5.1) are equal.

There are two aspects worth highlighting from this simulation. First, the price at which the multinational is indifferent between Mountain and Valley - the point at which it allocates half the firms in the Valley - occurs between 1 and 1.2 (when $N_{t} \psi=5$ ). Notice that the price at this indifferent point is much lower than the price at which the individuals are indifferent. The reason is that the value of continuation is marginally improved when $\psi$ is lowered from 1 , and therefore, the marginal contribution for the multinational is larger than for the individual firm.

Second, there is a kink at the top left for the multinational. This is the place where the optimal allocation in the Mountain would have implied less than one firm. However, because of the value matching condition, the multinational allocates a maximum of nine firms to the Valley. A similar kink occurs on the right side of 

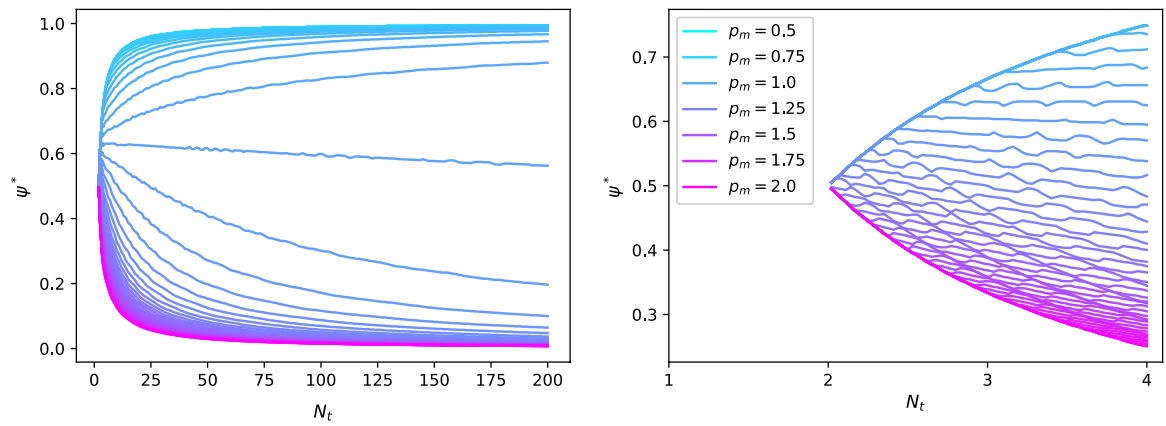

Fig. 13 Optimal policy as cost of Mountain changes

the graph, but the prices required to reach it are large - swamping the details of the graph presented.

\section{Discussion and Policy Implications}

Our model is quite minimalist and has the objective of highlighting the contrast between the possible alternatives of approaching the global supply chain problem. The most important result is that robustness in the presence of certain forms of uncertainty replicates a behavior that tends to be considered sub-optimal or irrational - firms follow a probability matching strategy. However, what does robustness looks in practice, and what can policy makers do to achieve such an arrangement?

We would love to have a tangible example of a robust global supply chain, but we do not. In this paper, we argue that robustness should be a stronger consideration for the design of supply chains, but that this has not been the case. Therefore, it is not surprising to us that there are many supply chain disruptions - during COVID19 and even in 2021 with the scarcity of CPUs. It is our opinion that just-in-time and just-in-case are not enough to remedy those shocks. Moreover, JIT and JIC will not provide assurances for shocks that are yet to come - for instance, those related to environmental disasters and social unrest. Therefore, instead of trying to find an example that is either extremely particular or not terribly important, we have decided to look at other industries that are designed for robustness. Those are the financial system and the postal services.

\subsection{Robustness in Practice}

The financial system is becoming more and more robust through time. This is driven by the fact that it is a sector where supply disruptions are extremely costly, and aggregate shocks tend to happen repeatedly. The financial industry continues to advance and become more resilient - this is a slow process, but the institutions of 


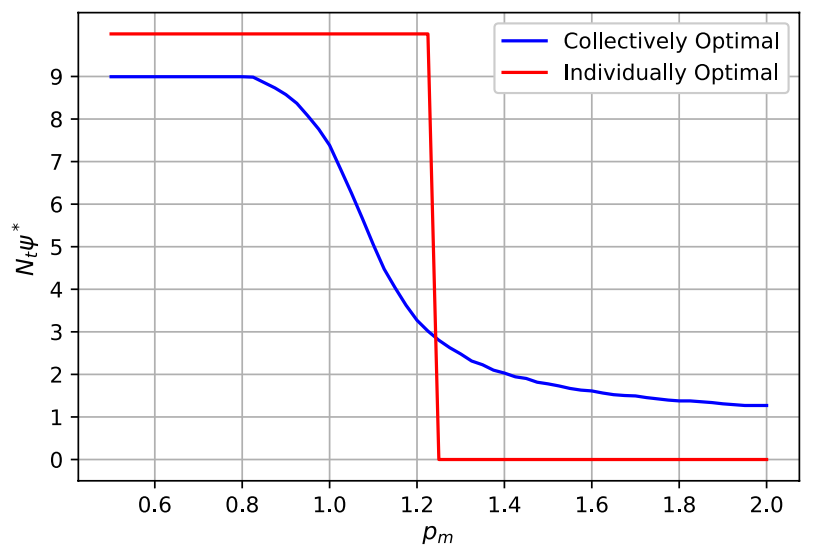

Fig. 14 Individual vs. multinational optimal with heterogeneous prices

the modern banking system are ages ahead of those that existed at the beginning of the twentieth century. The banking system is safer today than ever before and that has allowed for unprecedented growth. ${ }^{24}$

The banking system has deposit insurance, cash and capital requirements, stress tests, specific rules to deal with failure, strict licenses of operation, and a lender or last resort. Most of these institutional improvements have been proposed after financial crises. Interestingly to us, supply disruptions have not tended to improve the institutional environment of the global supply chain.

First, the stress test implemented after the 2008 crisis is clearly a tool to evaluate the bank's performance in a set of extreme circumstances. It is by definition an statistic to measure the impact on the balance sheet in the worst case. In reality, the worst case for each bank can be a different combination of shocks. There are some cases in a supply chain - such as an internal production line - that stress tests are performed. Very rarely is this evaluated internationally, certainly not to the extent of achieving robustness to global shocks.

The second set of tools that are associated with robustness are those that deal with readiness to a shock. In this case, capital requirements and cash reserves are designed to protect the balance sheet to contingent loses. Failure of the stress tests or the provision of capital requirements has consequences for financial institutions. These sometimes include limiting the ability of the risky bank to continue operating, and even the removal of its license to operate.

The third set of policies deal with the "clients" behavior. In the example of the banking system, the clients are the depositors. The objective of a federal deposit

\footnotetext{
${ }^{24}$ In fact, if we were to take the current regulatory environment and the size and activities of the banking system of 100 years ago, the probability of a financial crisis would be virtually zero. The increased resilience and trust allows for the financial sector to continue expanding - which creates new opportunities of disruption and subsequently new opportunities to improve it.
} 
insurance is to stop bank runs - or at least to reduce their severity and frequency. Again, this is a policy that is entirely designed to deal with an extreme shock.

Finally, the existence of a lender of last resort works in conjunction with the previous regulatory tools. It makes the deposit insurance credible, and it creates the residual claimant of the stress tests and the capital requirements. Therefore, there exists someone in the economy that is really concerned with the rescue of the banks because it is extremely costly for them. One important aspect of the single residual claimant of a banking crises is the ability to handle the informational frictions that are likely to appear. This institutional arrangement offers social insurance to the banking system, which leads to the standard moral hazard and adverse selection problems. It is important in this design to take into account those issues. During the COVID-19 crisis, we indeed observed a "lender of last resort" in the form of fiscal and monetary policy support to firms and citizens. However, these were reactionary policies, and if used repeatedly without proper design may create bad incentives.

When we think about the global supply chain, (i) there is a lack of stress tests, (ii) most suppliers are independent and therefore there is little ability to enforce proper firm health (equivalent to a capital requirement), (iii) there is no institution that compensates clients for failures of the suppliers (analogous to the FDIC), and (iv) only in the case when all the suppliers belong to a single firm can we find a residual claimant (the lender of last resort). We hope this makes clear why supply chain failures happen so regularly, and why ex-post these shocks look easy to deal with - such as occurred with isopropyl alcohol and toilet paper.

We are obviously not advocating for a central bank equivalent of global supply chains. We are, however, highlighting the fact that firms can design for and assess robustness ex-ante. Stress testing is simple to implement and can even be a part of the supply contract. Furthermore, capital requirements or financial health is usually evaluated in some international relationships (such as joint ventures) but a process of certification that is transparent and standardized would be more effective than dealing with these issues on a case-by-case basis.

There is a final aspect of robust supply chains that is hard to see in the financial system - even though it exists. Probability matching implies resilience though redundancies. A robust supply chain will have excess capacity that seems very costly in normal times, because that excess capacity exists to be used if the extreme shock occurs. It is exactly the opposite of just-in-time and on average contradicts just-in-case, which presumably implies that only half the time it has excess capacity. The financial system has this excess capacity built into the tools we describe, but this is more easily seen in the postal service. The postal service is a very robust supply chain. Notice the elements: one residual claimant, continuous stress testing, and excess capacity in normal times. In fact, the postal service has so much excess capacity that people in general argue that it is too inefficient. We are not arguing that the postal service is efficient. We are highlighting that such a statement cannot be made in the absence of robust thinking. If the postal service has been designed with robustness in mind, it needs to look inefficient during normal times. This problem is even harder to resolve in the global supply chain. The reason is that excess capacity requires not only physical capital but also human capital. Multinationals need to develop production capabilities in countries where, in normal times, it seems like a 
bad decision to do so or a luxury the firm can avoid. Of course, these assessments lead to underinvestment in production capabilities; when the shock hits, the regret of not having invested settles in.

\subsection{Uncertainty and Price Gouging in Reality}

The two most important elements of our model are the existence of uncertainty and the failure of prices to fully adjust. Uncertainty occurs when the distribution of a model parameter is unknown, but it can fall only within a range. In macroeconomics, uncertainty is pervasive and rightfully so. Many shocks of different natures affect the economy and are transmitted through complex and unobservable networks that shifting through time. Not surprisingly then, central bankers experience such uncertainty and even "talk in ranges."

For example, Fig. 15 shows the range of Economic projections of the Federal Reserve Board members and Federal Reserve Bank presidents, each operating under their individual assumptions of projected appropriate monetary policy. More precisely, each board member of the Fed adopts a different economic model, which gives its own predictions. The Fed needs to decide monetary policy based on this set of models. While the report did not particularly state that policymaking is driven by the worst case, on many occasions the Fed speeches have mentioned avoiding the worst-case outcome.

In fact, as argued by Sargent and Hansen, uncertainty is the natural outcome of an estimation process where multiple models are acceptable. Uncertainty in our economic and policy models should be the norm, although unfortunately it is not. We believe that this failure may lead to bad policy choices - thereby increasing the risk our economies are subjected to and the likelihood that living standards deteriorate.

The second important element in our model is price gouging. For example, if firms knew ex-ante that prices would be allowed to increase to their fullest extent, then firms would individually choose to diversify until locating in the Mountain or the Valley has the same expected returns. There were several events during COVID19 that show that prices did not adjust to this extent. First, many countries have price gouging laws that limit firms' ability to increase prices. So, after a supply shock prices would increase - but not fully. Second, in many countries, lawsuits began accusing firms of abusive behavior - most of which were related to price increases. Third, even when prices for some goods increased, we saw stock-outs and rationing of products - clearly signaling that the demand was higher than the supply and prices could not have been at equilibrium. As we have said before, we know that price gouging as modeled here is an extreme assumption. The supply disruptions and rationing that occurred in developed nations for products such as food, beverages, personal care, etc., indicates that prices never increased enough for it to be profitable for the supply chain to diversify and prepare for large aggregate shocks. to the point at which it is profitable for the supply chain to prepare for large aggregate shocks. Our results in this paper will qualitatively hold as long as prices do not adjust fully. 


\begin{tabular}{|c|c|c|c|c|c|c|c|c|c|c|c|c|c|c|c|}
\hline \multirow{2}{*}{ Variable } & \multicolumn{5}{|c|}{ Median } & \multicolumn{5}{|c|}{ Central tendency } & \multicolumn{5}{|c|}{ Range } \\
\hline & 2020 & 2021 & 2022 & 2023 & $\begin{array}{l}\text { Longer } \\
\text { run }\end{array}$ & 2020 & 2021 & 2022 & 2023 & $\begin{array}{c}\text { Longer } \\
\text { run }\end{array}$ & 2020 & 2021 & 2022 & 2023 & $\begin{array}{l}\text { Longer } \\
\text { run }\end{array}$ \\
\hline Change in real GDP $\ldots$. & -2.4 & 4.2 & 3.2 & 2.4 & 1.8 & $-2.5--2.2$ & $3.7-5.0$ & $3.0-3.5$ & $2.2-2.7$ & $1.7-2.0$ & $-3.3--1.0$ & $0.5-5.5$ & $2.5-4.0$ & $2.0-3.5$ & $1.6-2.2$ \\
\hline September projection & -3.7 & 4.0 & 3.0 & 2.5 & 1.9 & $-4.0--3.0$ & $3.6-4.7$ & $2.5-3.3$ & $2.4-3.0$ & $1.7-2.0$ & $-5.5-1.0$ & $0.0-5.5$ & $2.0-4.5$ & $2.0-4.0$ & $1.6-2.2$ \\
\hline Unemployment rate & 6.7 & 5.0 & 4.2 & 3.7 & 4.1 & $6.7-6.8$ & $4.7-5.4$ & $3.8-4.6$ & $3.5-4.3$ & $3.9-4.3$ & $6.6-6.9$ & $4.0-6.8$ & $3.5-5.8$ & $3.3-5.0$ & $3.5-4.5$ \\
\hline September projection & 7.6 & 5.5 & 4.6 & 4.0 & 4.1 & $7.0-8.0$ & $5.0-6.2$ & $4.0-5.0$ & $3.5-4.4$ & $3.9-4.3$ & $6.5-8.0$ & $4.0-8.0$ & $3.5-7.5$ & $3.5-6.0$ & $3.5-4.7$ \\
\hline PCE inflation. & 1.2 & 1.8 & 1.9 & 2.0 & 2.0 & 1.2 & $1.7-1.9$ & $1.8-2.0$ & $1.9-2.1$ & 2.0 & $1.1-1.4$ & $1.2-2.3$ & $1.5-2.2$ & $1.7-2.2$ & 2.0 \\
\hline September projection & 1.2 & 1.7 & 1.8 & 2.0 & 2.0 & $1.1-1.3$ & $1.6-1.9$ & $1.7-1.9$ & $1.9-2.0$ & 2.0 & $1.0-1.5$ & $1.3-2.4$ & $1.5-2.2$ & $1.7-2.1$ & 2.0 \\
\hline Core PCE inflation ${ }^{4} \ldots$ & 1.4 & 1.8 & 1.9 & 2.0 & & 1.4 & $1.7-1.8$ & $1.8-2.0$ & $1.9-2.1$ & & $1.3-1.5$ & $1.5-2.3$ & $1.6-2.2$ & $1.7-2.2$ & \\
\hline September projection & 1.5 & 1.7 & 1.8 & 2.0 & & $1.3-1.5$ & $1.6-1.8$ & $1.7-1.9$ & $1.9-2.0$ & & $1.2-1.6$ & $1.5-2.4$ & $1.6-2.2$ & \begin{tabular}{l|l}
$1.7-2.1$ \\
\end{tabular} & \\
\hline \multicolumn{16}{|l|}{$\begin{array}{l}\text { Memo: Projected } \\
\text { appropriate policy path }\end{array}$} \\
\hline Federal funds rate & 0.1 & 0.1 & 0.1 & 0.1 & 2.5 & 0.1 & 0.1 & 0.1 & $0.1-0.4$ & $2.3-2.5$ & 0.1 & 0.1 & $0.1-0.4$ & $0.1-1.1$ & $2.0-3.0$ \\
\hline September projection & 0.1 & 0.1 & 0.1 & 0.1 & 2.5 & 0.1 & 0.1 & 0.1 & $0.1-0.4$ & $2.3-2.5$ & 0.1 & 0.1 & $0.1-0.6$ & $0.1-1.4$ & $2.0-3.0$ \\
\hline
\end{tabular}

Fig. 15 Economic projections of Federal Reserve Board members and Federal Reserve Bank presidents, December 2020, reported in the Monetary Policy Report of February 2021

Furthermore, we see countries provide price incentives to curtail just-in-time practices. As shown in Fig. 13, there is a price of Mountain-produced goods for which the multinational's optimal policy implies diversification similar to the robust policy. In fact, a similar heterogeneity of prices can make individual suppliers replicate the robust policy as well. Therefore, a subsidy given to firms in riskier locations can help achieve the robust allocation.

This conclusion is important because governments and the private sector might experience risk differently. Typically, governments are the residual claimant in case of natural disasters. Therefore, governments are more likely to prefer a "robust approach" than the private sector would. For instance, if the cost of a natural disaster is very asymmetric, the government is more likely to pay attention to the worst-case than the private sector. If this is indeed the case, the government can align private incentives by providing a small subsidy to the riskier location.

In fact, Japan is doing so as a response to COVID-19. In August of 2020, Japan set up a fund to compensate firms that diversify out of China - see Bloomberg News (2020). This is not the only example where countries are seeking to diversify the supply chain. Moreover, governments are also trying to change other aspects of the global economy. For example, Russia announced a tax break for companies that diversify away from dollar-denominated exporting contracts. In particular, if firms contract in Euros for their exports, they save on the domestic sales tax. The need to reduce international dependence on the dollar as a currency is an aspect that can also be understood through the lens of robustness.

\section{Conclusions}

COVID-19 was an aggregate shock that highlighted the weaknesses on the supply chain. Many products suffered disruptions: from personal protective equipment, to toilet paper, and beer. It is clear that the supply chains of the world were not prepared for this event. Many are imploring that "future" supply chains become more 
resilient or robust - but what exactly is a robust supply chain? and how exactly do firms' decisions change when taking a robust approach?

This paper studies a very stylized model of a supply chain. A multinational producing a product benefits from many suppliers providing parts, but those firms might not choose the best allocation of resources when aggregate shocks are present. Our model discusses how different arrangements of the supply chain emerge in different settings. In particular, we concentrate on two factors: (i) the internalization of the survival probability - in the spirit of the usual externalities; and (ii) the nature of the shock with either risk or uncertainty.

In this paper, a robust supply chain is that which optimally deals with uncertainty. It implies designing for the worst-case of a set of aggregate shocks. Robustness yields a strategy that seems to maximize survival probability, and therefore, our model rationalizes or explains the well known "probability matching" behavior observed in experimental literature. Probability matching is the result of a group decision process in which the number of people in the group who choose a given strategy is proportional to the probability that that strategy will yield survival. Probability matching is inefficient for individual decision makers, as it is optimal for them to maximize their own probability of survival. However, probability matching maximizes collective growth. To achieve, or at least to get close to probability matching, we need coordination between small decentralized suppliers - the market does not work properly during a crisis because the price system fails to signal scarcity correctly. A multinational can partially remedy this by considering continuation value, and fiscal support can help replicate the probability matching and robust allocation.

The robust solution needs a centralized decision maker who faces uncertainty. Our paper finishes with a discussion of policies in which the government can create circumstances in which the robust allocation is feasible for a decentralized supply chain. As an example, we briefly discuss the recent policies in Japan to subsidize diversification and reduce reliance on China.

Our paper leaves many research questions that could be addressed in the future. First, the relaxation of the identical price fixing period and investment horizons. Implicitly, the question is to evaluate quantitatively the importance of the anti-price gouging or partial price adjustment effects. Second, our model needs a market inefficiency to exist in order to break the first welfare theorem. This paper concentrates on such an inefficiency in the pricing system. However, it is conceivable that many other market imperfections could produce similar results. ${ }^{25}$ The role of robustness in those environments - with imperfect information, coordination failures, or externalities - might be a promising area of research. ${ }^{26}$

Finally, as we highlighted in this paper, robustness is not equivalent to assuming that shocks are larger or more severe; it is a fundamentally different strategy

\footnotetext{
${ }^{25}$ We thank David Baqaee for providing us with these future avenues of research.

${ }^{26}$ Other forms of inefficiencies can affect how costly the supply disruptions can be. In our model is a very simple mechanism, but see Baqaee and Farhi (2020) for a thorough study of misallocation in general equilibrium of different market imperfections.
} 
that addresses uncertainty by minimize the losses of the worst-case outcome. In doing so, it produces a different form of diversification. Increasing the variance of shocks is equivalent to arguing that the supply chain moves from just-in-time to just-in-case. Uncertainty, on the other hand, implies that the supply chain moves to Just-in-Worst-Case.

\section{Appendices}

\section{A Continuous-Time Model}

In the main body of this paper, we study a discrete-time model of supply chains and aggregate shocks. This section formulates a continuous-time model and studies the basic model, the effects of uncertainty, and finally price differences.

To derive a similar model to that of Sect. 3, but in continuous time, we need to define the stochastic process $N_{t}$ and the value function $v(n)$. We treat shocks to the Mountain or Valley as two independent Poisson counting processes $M_{t}$ and $V_{t}$, with intensity $\gamma \theta$ and $\gamma(1-\theta)$, respectively. Finally, we will assume that firms grow continuously in time, and discontinuities occur only when a shock arrives. Therefore, the number of firms evolves according to the following:

$$
d N_{t}=b\left(N_{t}\right) d t-\psi_{t} N_{t} d V_{t}-\left(1-\psi_{t}\right) N_{t} d M_{t} .
$$

We can write this stochastic differential equation in a general setting, but for consistency with Sect. 3, assume that $b\left(N_{t}\right)=A N_{t}^{1-\mu}-N_{t}$. Notice that our choice of the drift will yield a mean-reverting process.

The value function depends on a discount rate $\beta$ and a running reward $r\left(N_{t}\right)$. Similar to the discrete time model, we will let $r\left(N_{t}\right)=p N_{t}-c N_{t-}$, where $N_{t-}$ is the leftmost limit, so that the cost to produce is paid before any production occurs. The value function is then the integral of discounted profit:

$$
v(n)=\max _{\left(\psi_{s}\right)_{s \geq 0}} \mathbb{E}\left[\int_{0}^{\infty} e^{-\beta t} r\left(N_{t}\right) d t \mid N_{0}=n\right],
$$

where we require that $v(x)=0, \forall x \in[0,1)$ as the boundary condition, as in Sect. 3 .

Due to the fact that $v$ does not depend on time, and the process $N_{t}$ is Markovian, a dynamic programming argument means that we can re-write the value function as

$$
v(x)=\max _{\left(\psi_{s}\right)_{s \geq 0}} \mathbb{E}\left[\int_{0}^{t} e^{-\beta s} r\left(N_{s}\right) d s+e^{-\beta t} v\left(N_{t}\right) \mid N_{0}=x\right] .
$$

Next, we work to find the HJB differential equation for the value function. First, we apply Ito's Lemma to $f(t, x)=e^{-\beta t} v(x)$, which gives 


$$
\begin{aligned}
f\left(t, N_{t}\right)-f\left(0, N_{0}\right)= & \int_{0}^{t} \frac{d f}{d t}\left(s, N_{s}\right) d s+\int_{0}^{t} \frac{d f}{d x}\left(s, N_{s}\right) d N_{s} \\
& +\sum_{s \leq t, d V_{s}=1}\left[f\left(s, N_{s}\right)-f\left(s, N_{s-}\right)+\psi_{s} N_{s} \frac{d f}{d x}\left(s, N_{s}\right)\right] \\
& +\sum_{s \leq t, d M_{s}=1}\left[f\left(s, N_{s}\right)-f\left(s, N_{s-}\right)+\left(1-\psi_{s}\right) N_{s} \frac{d f}{d x}\left(s, N_{s}\right)\right] .
\end{aligned}
$$

After some simplification, using the definition of $f(t, x)$ and $N_{t}$, we arrive at the next step in our derivation:

$$
\begin{aligned}
e^{-\beta t} v\left(N_{t}\right)-v\left(N_{0}\right)= & \int_{0}^{t} e^{-\beta s}\left[b\left(N_{s}\right) v^{\prime}\left(N_{s}\right)-\beta v\left(N_{s}\right)\right] d s \\
& +\sum_{s \leq t, d V_{s}=1} e^{-\beta s}\left(v\left(N_{s}\right)-v\left(N_{s-}\right)\right) \\
& +\sum_{s \leq t, d M_{s}=1} e^{-\beta s}\left(v\left(N_{s}\right)-v\left(N_{s-}\right)\right) .
\end{aligned}
$$

The left-hand side of this expression is present in Eq. (A.2), which when plugged in yields

$$
\begin{aligned}
0= & \max _{\left(\psi_{s}\right)_{s \geq 0}} \mathbb{E}\left[\int_{0}^{t} e^{-\beta s}\left(r\left(N_{s}\right)+b\left(N_{s}\right) v^{\prime}\left(N_{s}\right)-\beta v\left(N_{s}\right)\right) d s\right. \\
& \left.+\int_{0}^{t} e^{-\beta s}\left(v\left(\left(1-\psi_{s}\right) N_{s}\right)-v\left(N_{s}\right)\right) d V_{s}+\int_{0}^{t} e^{-\beta s}\left(v\left(\psi_{s} N_{s}\right)-v\left(N_{s}\right)\right) d M_{s} \mid N_{0}=n\right] .
\end{aligned}
$$

Now, we use the definitions of $r\left(N_{s}\right)$ and $b\left(N_{s}\right)$ :

$$
\begin{aligned}
0= & \max _{\left(\psi_{s}\right)_{s \geq 0}} \mathbb{E}\left[\int_{0}^{t} e^{-\beta s}\left((p-c) N_{s}+\left(A N_{s}^{1-\mu}-N_{s}\right) v^{\prime}\left(N_{s}\right)-\beta v\left(N_{s}\right)\right) d s\right. \\
& +\int_{0}^{t} e^{-\beta s}\left(v\left(\left(1-\psi_{s}\right) N_{s}\right)-v\left(N_{s}\right)-p \psi_{s} N_{s}\right) d V_{s} \\
& \left.+\int_{0}^{t} e^{-\beta s}\left(v\left(\psi_{s} N_{s}\right)-v\left(N_{s}\right)-p\left(1-\psi_{s}\right) N_{s}\right) d M_{s} \mid N_{0}=n\right] .
\end{aligned}
$$

Finally, we divide both sides by $t$ and take the limit as $t \rightarrow 0$. Making use of the intensities of the counting processes $M_{t}$ and $V_{t}$, we find the HJB equation for the value function:

$$
\begin{aligned}
0= & (p-c) x+\left(A x^{1-\mu}-x\right) v^{\prime}(x)-(\gamma+\beta) v(x) \\
& +\max _{\psi} \gamma[(1-\theta)(v((1-\psi) x)-p \psi x)+\theta(v(\psi x)-p(1-\psi) x)] \\
v(x)= & 0, \forall x \in[0,1) .
\end{aligned}
$$


This expression is a nonlinear first-order ordinary differential equation. If the maximization problem is concave, we can solve for the first-order condition to find the optimal $\psi^{*}$, which will satisfy:

$$
\frac{1-\theta}{\theta}=\frac{p+v^{\prime}\left(\psi^{*} x\right)}{p+v^{\prime}\left(\left(1-\psi^{*}\right) x\right)}
$$

as long as $\psi^{*} x \geq 1$ and $\left(1-\psi^{*}\right) x \geq 1$.

The optimal allocation satisfies a "probability matching" of sorts: The ratio of short-term profit $(p)$ plus long-term marginal benefit $\left(v^{\prime}\right)$ must equal the ratio of aggregate shock probabilities. In particular, if $v^{\prime}(1)=\infty$, then the multinational will choose an interior solution.

\section{A.1 Uncertainty}

When presented with uncertainty, we can also study the robust minimax problem of Sect. 4. Again, we assume that $\theta \in[\bar{\theta}-\Delta, \bar{\theta}+\Delta]$. Now, the multinational's value function is given by

$$
v(n)=\max _{\left(\psi_{s}\right)_{s \geq 0}} \min _{\theta \in[\bar{\theta}-\Delta, \bar{\theta}+\Delta]} \mathbb{E}\left[\int_{0}^{\infty} e^{-\beta t} r\left(N_{t}\right) d t \mid N_{0}=n\right],
$$

and the corresponding $\mathrm{HJB}$ is

$$
\begin{aligned}
0= & (p-c) x+\left(\frac{1}{1-\mu} x^{1-\mu}-x\right) v^{\prime}(x)-(\gamma+\beta) v(x) \\
& +\max _{\psi} \min _{\theta \in[\bar{\theta}-\Delta, \bar{\theta}+\Delta]} \gamma[(1-\theta)(v((1-\psi) x)-p \psi x)+\theta(v(\psi x)-p(1-\psi) x)] \\
v(x)= & 0, \forall x \in[0,1) .
\end{aligned}
$$

First, we study the first-order condition for the minimization problem. For a fixed $\psi$, the function to minimize is linear in $\theta$ :

$$
(v((1-\psi) x)-p \psi x)+\theta[v(\psi x)-p(1-\psi) x-v((1-\psi) x)+p \psi x] .
$$

Nature's optimal choice of $\theta$ will be an extreme value. If the quantity in the brackets is negative (or positive), the optimal $\theta^{*}$ is $\bar{\theta}+\Delta$ (or $\bar{\theta}-\Delta$, respectively). Formally,

$$
\theta^{*}= \begin{cases}\bar{\theta}+\Delta & \text { if } v\left(\psi N_{t}\right)-v\left((1-\psi) N_{t}\right)<p(1-2 \psi) N_{t} \\ \bar{\theta}-\Delta & \text { if } v\left(\psi N_{t}\right)-v\left((1-\psi) N_{t}\right)>p(1-2 \psi) N_{t}\end{cases}
$$

Notice that the choice $\psi=0.5$ makes nature indifferent among all $\theta$. Here lie the effects of robustness: If $\Delta$ is large, nature can significantly punish the multinational for choosing $\psi \neq 0.5$, but if $\Delta$ is small, the robust optimum may choose a larger $\psi$ and lose fewer firms. The message is the same - uncertainty rewards optimizing the worst-case outcome. 
Finally, the first-order conditions for $\psi$ will give the same expression as in the previous section, but with $\theta=\theta^{*}$.

\section{A.2 Heterogeneous Prices}

We now study the analogue of Sect. 5 by allowing prices to be different. Due to linearity of our system, heterogeneous prices will give the same qualitative results as heterogeneous costs.

Let us consider how the optimal solution changes if $p_{m}>p_{v}$. Now, the only difference is that

$$
r\left(N_{t}\right)=N_{t}\left(p_{v} \psi\left(1-d V_{t}\right)+p_{m}(1-\psi)\left(1-d M_{t}\right)-c\right) .
$$

Following the derivation from before, we find that the HJB for the value function is

$$
\begin{aligned}
0= & -c x+\left(A x^{1-\mu}-x\right) v^{\prime}(x)-(\gamma+\beta) v(x) \\
& +\max _{\psi}\left(p_{v} \psi+p_{m}(1-\psi)\right) x+\gamma\left[(1-\theta)\left(v((1-\psi) x)-p_{v} \psi x\right)+\theta\left(v(\psi x)-p_{m}(1-\psi) x\right)\right] \\
v(x)= & 0, \quad \forall x \in[0,1) .
\end{aligned}
$$

Under similar concavity conditions, the optimal $\psi^{*}$ will satisfy:

$$
\frac{p_{m}-p_{v}}{\gamma}=\theta\left[v^{\prime}\left(\psi^{*} x\right)+p_{m}\right]-(1-\theta)\left[v^{\prime}\left(\left(1-\psi^{*}\right) x\right)+p_{v}\right] \text {. }
$$

Rearranging, the first-order condition becomes:

$$
\frac{1-\theta}{\theta}=\frac{\left(1-\frac{1}{\gamma \theta}\right) p_{m}+v^{\prime}\left(\psi^{*} x\right)}{\left(1-\frac{1}{\gamma(1-\theta)}\right) p_{v}+v^{\prime}\left(\left(1-\psi^{*}\right) x\right)} .
$$

This is again a probability matching solution. Note that both coefficients of $p_{m}$ and $p_{v}$ are negative, and therefore, if $p_{m}$ is large, then $v^{\prime}\left(\psi^{*} x\right)$ must also be large, which we expect implies a small $\psi$. This indicates that we may be able to re-create any allocation through the choice of a suitable $p_{m}$.

Additionally, the arrival probability of the aggregate shock plays a role in this expression. If $\gamma$ is close to one, then the multinational's decision is heavily dictated by the ratio of marginal values of firms, and the price differences are ignored. However, if $\gamma$ is small, then the ratio of prices is more important.

\section{References}

Alfaro, L., D. Chor, P. Antras, and P. Conconi. 2019. Internalizing global value chains: a firm-level analysis. Journal of Political Economy 127 (2): 508-559.

Ambulkar, S., J. Blackhurst, and S. Grawe. 2015. Firm's resilience to supply chain disruptions: scale development and empirical examination. Journal of Operations Management 33: 111-122. 
Anderson, D., and P. Apfel. 2020. Covid-19 global impact: a world tour of competition law enforcement (4 "tracker maps"). https://www.concurrences.com.

Anderson, E., N. Jaimovich, and D. Simester. 2015. Price stickiness: empirical evidence of the menu cost channel. Review of Economics and Statistics 97 (4): 813-826.

Antras, P. 2003. Firms, contracts, and trade structure. The Quarterly Journal of Economics 118 (4): 1375-1418.

Antras, P. 2015. Global production: firms, contracts, and trade structure. Princeton University Press.

Antràs, P. 2020. Conceptual aspects of global value chains. The World Bank.

Antràs, P., and D. Chor. 2013. Organizing the global value chain. Econometrica 81 (6): 2127-2204.

Antràs, P., and D. Chor. 2018. On the measurement of upstreamness and downstreamness in global value chains. World Trade Evolution: Growth, Productivity and Employment, 126-194

Antràs, P., and A. De Gortari. 2020. On the geography of global value chains. Econometrica 88 (4): 1553-1598.

Baqaee, D.R., and E. Farhi. 2020. Productivity and misallocation in general equilibrium. The Quarterly Journal of Economics 135 (1): 105-163.

Bloomberg News. 2020. Japan starts paying firms to cut reliance on Chinese factories. https://www. bloomberg.com.

Brennan, T.J., and A.W. Lo. 2011. The origin of behavior. The Quarterly Journal of Finance 1 (01): $55-108$.

Caballero, R.J., and E. Engel. 2006. Price stickiness in ss models: basic properties. MIT (unpublished).

Cary, G.S., M.J.F.M. Dolmans, B. Hoffman, T. Graf, L. Brannon, R. Pepper, H. Mostyn, A.R.B. Lazda, S. Haynes, K. Georgieva, and J. Przerwa. 2020. Exploitative abuses, price gouging \& covid-19: the cases pursued by EU and national competition authorities. https://www.concurrences.com.

Durach, C.F., and J.A. Machuca. 2018. A matter of perspective-the role of interpersonal relationships in supply chain risk management. International Journal of Operations \& Production Management, 38(10): 1866-1887.

Dworczak, P., Kominers, S. D., and Akbarpour, M. (2021). Redistribution through markets. Econometrica, 89(4): 1665-1698.

Evans, D. 2020. Coronavirus shows that supply chains are outdated and unfit for modern manufacturing. https://www.forbes.com.

Fiorina, M.P. 1971. A note on probability matching and rational choice. Behavioral Science 16 (2): 158-166.

Gaissmaier, W., and L.J. Schooler. 2008. The smart potential behind probability matching. Cognition 109 (3): 416-422.

Gilboa, I., and D. Schmeidler. 1989. Maxmin expected utility with non-unique prior. Journal of mathematical economics 18 (2): 141-153.

Hallegatte, S. 2015. The indirect cost of natural disasters and an economic definition of macroeconomic resilience. The World Bank.

Hansen, L. P., and T.J. Sargent. 2011. Robustness. Princeton university press.

Helpman, E., M.J. Melitz, and S.R. Yeaple. 2004. Export versus FDI with heterogeneous firms. American economic review 94 (1): 300-316.

Kahneman, D., S.P. Slovic, P. Slovic, and A. Tversky. 1982. Judgment under uncertainty: heuristics and biases. Cambridge University Press.

Kahneman, D., and A. Tversky. 1979. Prospect theory: an analysis of decision under risk. Econometrica 47: 263-291.

King and Spalding. 2020. Covid-19 survey of federal and state price gouging laws. https://www.kslaw. com.

Kremer, M. 1993. The o-ring theory of economic development. The Quarterly Journal of Economics 108 (3): 551-575.

Lo, A.W. 2017. Adaptive markets. Princeton University Press.

Evans, D. 2020. Coronavirus shows that supply chains are outdated and unfit for modern manufacturing. https://www.forbes.com.

Melitz, M.J. 2003. The impact of trade on intra-industry reallocations and aggregate industry productivity. Econometrica 71 (6): 1695-1725.

Morse, E.B., and W.N. Runquist. 1960. Probability-matching with an unscheduled random sequence. The American journal of psychology 73 (4): 603-607.

Plenert, G. 2007. Reinventing lean: introducing lean management into the supply chain. Oxford: Butterworth-Heinemann. 
Rotemberg, J.J. 2002. Customer anger at price increases, time variation in the frequency of price changes and monetary policy. Technical report, National Bureau of Economic Research.

Rotemberg, J.J. 2011. Fair pricing. Journal of the European Economic Association 9 (5): 952-981.

Saenz, M.J., X. Koufteros, C.F. Durach, A. Wieland, and J.A. Machuca. 2015. Antecedents and dimensions of supply chain robustness: a systematic literature review. International Journal of Physical Distribution \& Logistics Management, 45, 118-137.

Seth, A.K. 2007. The ecology of action selection: insights from artificial life. Philosophical Transactions of the Royal Society B, 362, 1545-1558.

Sion, M., et al. 1958. On general minimax theorems. Pacific Journal of mathematics 8 (1): 171-176.

Strzalecki, T. 2011. Axiomatic foundations of multiplier preferences. Econometrica, 79 (1): 47-73.

The FT Editorial Board. 2020. Companies should shift from "just in time" to "just in case". Financial Times.

Todd, P.M., and Gigerenzer, G.E. 2012. Ecological rationality: Intelligence in the world. Oxford University Press.

Töyli, J., H. Lorentz, L. Ojala, A. Wieland, and C.M. Wallenburg. 2013. The influence of relational competencies on supply chain resilience: a relational view. International Journal of Physical Distribution \& Logistics Management, 23, 300-320.

Tran, Brigitte Roth, and Daniel J. Wilson. 2020. The Local Economic Impact of Natural Disasters. FRB San Francisco Working Paper, 2020-2034.

UK Competition Authority. 2020. The UK competition authority publishes update on its covid-19 taskforce, including a number of excessive pricing complaints and investigations. https://www.concu rrences.com.

Vickery, S.N, R. Calantone, and C. Dröge. 1999. Supply chain flexibility: an empirical study. Journal of supply chain management 35 (2): 16-24.

Vulkan, N. 2000. An economist's perspective on probability matching. Journal of economic surveys 14 (1): 101-118.

Wagner, S.M., and C. Bode. 2006. An empirical investigation into supply chain vulnerability. Journal of purchasing and supply management 12 (6): 301-312.

Yeaple, S.R. 2003. The complex integration strategies of multinationals and cross country dependencies in the structure of foreign direct investment. Journal of International Economics 60 (2): 293-314.

Zhao, S., and F. You. 2019. Resilient supply chain design and operations with decision-dependent uncertainty using a data-driven robust optimization approach. AIChE Journal 65 (3): 1006-1021.

Publisher's Note Springer Nature remains neutral with regard to jurisdictional claims in published maps and institutional affiliations.

Bomin Jiang obtained his Ph.D. from the Institute for Data, Systems and Society, Massachusetts Institute of Technology (MIT), and a B.E. degree with First Class Honours from The Australian National University. In August 2014, he was awarded the University Medal from the Australian National University. In September 2017, he was awarded the MIT Presidential Fellowship. His current research interests span multiple areas of macroeconomics.

Daniel Rigobon is a PhD Student at the Department of Operations Research and Financial Engineering at Princeton University. He graduated from MIT in 2018 with a B.S. in Mechanical Engineering, where he was a member of the Pi Tau Sigma honor society. In May of 2018, he received the John C. and Elizabeth J. Chato Award from MIT, and in September of the same year, the Presidents' Fellowship from Princeton. His research interests are broadly in fragility of networked systems, latent variable models, and fairness in machine learning.

Roberto Rigobon obtained his PHD from the economics department at MIT, his MBA from IESA (venezuela), and his Engineering Bachelors degree from Universidad Simon Bolivar. His research spans multiple areas of macroeconomics, development economics, and international economics. 


\section{Authors and Affiliations}

Bomin Jiang ${ }^{1} \cdot$ Daniel Rigobon $^{2} \cdot$ Roberto Rigobon $^{3}$

Bomin Jiang

bominj@mit.edu

Daniel Rigobon

drigobon@princeton.edu

1 MIT, IDSS, Cambridge, MA, USA

2 Princeton, ORFE, Princeton, NJ, USA

3 MIT and NBER, Cambridge, MA, USA 